\title{
3D geomechanical modeling of the response of the Wilzetta Fault to saltwater disposal
}

\author{
Behzad Hemami, Shahla Feizi Masouleh, and Ahmad Ghassemi* \\ Mewbourne School of Petroleum and Geological Engineering, University of Oklahoma, Norman, OK, USA \\ Key Points: \\ - We constructed a 3D fully coupled geomechanical model to study the response of the Wilzetta Fault to saltwater disposal. \\ - Injection in either a semi-restricted zone or an infinitely open one caused fault instability in 2001 (10 years before the main events in \\ 2011). \\ - Continuous injection in a fully bounded zone caused pore pressure increase, and led to fault failure in 2011.
}

Citation: Hemami, B., Masouleh, S. F., and Ghassemi, A. (2021). 3D geomechanical modeling of the response of the Wilzetta Fault to saltwater disposal. Earth Planet. Phys., 5(6), 559-580. http://doi.org/10.26464/epp2021054

\begin{abstract}
From 2009 to 2017, parts of Central America experienced marked increase in the number of small to moderate-sized earthquakes. For example, three significant earthquakes $\left(\sim M_{w} 5\right)$ occurred near Prague, Oklahoma, in the U. S. in 2011. On 6 Nov 2011 , an $M_{\mathrm{w}} 5.7$ earthquake occurred in Prague, central Oklahoma with a sequence of aftershocks. The seismic activity has been attributed to slip on the Wilzetta fault system. This study provides a 3D fully coupled poroelastic analysis (using FLAC3D) of the Wilzetta fault system and its response to saltwater injection in the underpressured subsurface layers, especially the Arbuckle group and the basement, to evaluate the conditions that might have led to the increased seismicity. Given the data-limited nature of the problem, we have considered multiple plausible scenarios, and use the available data to evaluate the hydromechanical response of the faults of interest in the study area. Numerical simulations show that the injection of large volumes of fluid into the Arbuckle group tends to bring the part of the Wilzetta faults in Arbuckle group and basement into near-critical conditions.
\end{abstract}

Keywords: poroelasticity; Oklahoma seismicity; Arbuckle group; saltwater injection; Wilzetta fault; 2011 Prague earthquake sequence

\section{Introduction}

Induced seismicity is associated with an injection (or production) operation in the subsurface which perturbs the in-situ pore pressure and total and effective stresses (Healy et al., 1968; Raleigh et al., 1976; Hsieh and Bredehoeft, 1981; Pearson, 1981; Phillips et al., 1997; McGarr et al., 2002; Suckale, 2009; National Research Council, 2013). Injection into subsurface formations is a common practice in many engineering applications such as enhanced oil recovery (EOR), hydrocarbon and geothermal reservoir stimulation, disposal of oil and gas co-produced water, and disposal of nuclear wastes. "Flow-back" water after multistage hydraulic fracturing operation is usually reinjected into the subsurface formation through class II underground injection control (UIC) wells. Saline water co-produced with oil and gas is also injected through these wells. The physical process of induced seismicity in relation to pore pressure increase has been addressed in many studies (Cheng AHD, 2016; Suckale, 2009). Subsurface injection changes both the pore pressure and the total stresses. The elevated pore pressure due to the fluid diffusion causes reduction and increase in effective and total stresses, respectively. As such, the effect of

Correspondence to: A. Ghassemi, ahmad.ghassemi@ou.edu

Received 27 DEC 2021; Accepted 13 JUL 2021.

Accepted article online 26 OCT 2021.

(C)2021 by Earth and Planetary Physics. injection on the fault stability would seem obvious: excess pore pressure causes decrease of the normal effective stress on the fault plane, and facilitates fault reactivation (Healy et al., 1968; Raleigh et al., 1976; Hsieh and Bredehoeft, 1981). However, the site-specific aspects of the phenomenon are complex. For example, it is challenging to determine the flow path of the injected fluid volume, the specific fault segments that slip, and the injection rates and volumes that may not lead to the occurrence of significant events in a given setting. These questions can be addressed by 3D geomechanical modeling that captures the salient aspects of the geological conditions and geomechanics effects.

Small- to moderate-sized earthquakes in the central and eastern United States were historically rare until 2009. Among all states, Oklahoma has experienced the greatest increase in the number of earthquakes. The rate of $M_{\mathrm{w}}>4$ earthquakes has increased from one per decade before 2009 to 24 in 2014 (Holland et al., 2014; Petersen et al., 2017). At the same time, the volume of injection has been increased significantly. For instance, the monthly injection volume in the state increased from 80 to 160 million barrels/month, primarily performed through saltwater disposal wells (SWD). Many authors have suggested that these earthquakes are related to increasing saltwater disposal produced during unconventional oil and gas production (Horton, 2012; Kim, 2013; Keranen et al., 2013, 2014; Frohlich et al., 2011, 2014). The 
$M_{\mathrm{w}}$ 5.7, 2011 event in Oklahoma occurred in Prague, central Oklahoma. It happened after many foreshocks and was followed by a sequence of aftershocks (including a foreshock and an aftershock, both $M_{\mathrm{w}}=4.8$, on 5 and 7 Nov 2011, respectively, Oklahoma Geological Survey (OGS)). These earthquakes were felt in at least 17 states (over 100 widely scattered ZIP codes at distances greater than $1000 \mathrm{~km}$ ) resulted in elevated increase of concerns about ongoing unconventional oil and gas activities (Keranen et al., 2013; Hough, 2014). Since these events occurred in the vicinity of active injection wells, some authors have proposed that they were induced by injection of oil and gas co-produced wastewater (Keranen et al., 2013, 2014; Sumy et al., 2014; Sun XD and Hartzell, 2014). Others have attributed the events to intra-plate tectonics (e.g., Keller and Holland, 2013). Analysis of such an important and complicated problem requires application of realistic models of pore pressure/stress alteration and fault systems interaction. In previous studies of seismicity in Oklahoma, the main focus has been on the pore pressure effect without addressing the rock mass deformation. Moreover, some previous work has been limited to 2D modeling (Deng $\mathrm{K}$ et al., 2020). In this work, we study the effect of wastewater injection on the pore pressure and total in-situ stress changes within the Wilzetta fault zone near Prague, Oklahoma. Rock mechanical and hydraulic properties of different layers and the fault system are used to construct the coupled fluid-mechanical model to investigate multi-year injection scenarios.

As mentioned, the primary process for injection-induced earthquakes is increased pore pressures that decrease the effective normal stress on the fault and cause faults to slip under the ambient stress state. Nevertheless, this is not the only process that controls the subsurface fault reactivation. Pore pressure changes also lead to additional poroelastic stress which may contribute to fault slip. The theory of poroelasticity and observations at injection target (or depleted hydrocarbon) reservoirs indicate that the in-situ stress field does not remain constant, and evolve during injection (or depletion) in time and space (Biot, 1941; Rice and Cleary, 1976; Segal, 1989; Lorenz et al., 1991; Cheng, 2016). The controlling parameters of the in-situ stress change are dependent on the sitespecific hydromechanical properties and structural geometry.

Fluid injection tends to expand the reservoir rock, whereas the neighboring rocks resist expansion in the horizontal direction. Therefore, injection causes induced compressive stress in the injection site. This stress decays to zero and then becomes tensile due to strain compatibility requirements. The dilated zone, pulls on the surrounding rock leading to the zone of horizontal extension in the neighboring rocks above and below the reservoir.

In the injection target reservoir (and in general where the pore pressure is increased due to the injection), the induced normal traction on fault increases due to the poroelastic effect, resulting in increased stability if the fault is within the poroelastic compression. Tensile stresses develop ahead of the compressional domain which can be destabilizing. The magnitude of the poroelastic stress is a function of the rock poroelastic properties. The stress change is also transferred to the rocks above and below, affecting fault reactivation in those zones. Cooling and development of thermal stress may also cause fracture/fault instability (Ghassemi and Tao QF, 2016). However, its potential effect on Oklahoma seis- micity has not been analyzed.

To evaluate fault reactivation potential, here we use the MohrCoulomb failure criterion and define a failure potential as CFS= $\tau_{\mathrm{s}}-\mu\left(\sigma_{\mathrm{n}}-P_{\mathrm{p}}\right)$, where $\mu$ is the coefficient of friction, $P_{\mathrm{p}}$ is pore fluid pressure, and $\tau_{\mathrm{s}}$ and $\sigma_{\mathrm{n}}$ are shear and total normal tractions acting on the fault, respectively. The sign convention is compression positive. A positive CFS shows fault reactivation. The pore pressure and poroelastic effects are considered in this paper using fully coupled 3D modeling. First, we briefly describe the geological model and numerical approach. Then we present simulation results for different plausible flow scenarios from the injection well to the critical zones with observed seismicity.

\section{Data and Methods}

\subsection{The Wilzetta Fault Zone}

Figure 1 shows the area of interest in the Oklahoma faults map (Oklahoma Geological Survey (OGS), http://www.ou.edu/ogs/ data/fault, the blue box), location of the injection wells (Oklahoma Corporation Commission (OCC), http://www.occeweb. com/og/ogdatafiles2.htm), and seismic events between 2009 and 2011 in the area of interest (OGS, http://www.ou.edu/ogs/research/earthquakes/catalogs). The area of interest is approximately $\sim 1200$ square kilometers (approximately $\sim 34 \mathrm{~km} \times 36 \mathrm{~km}$ ) and is located in the northern Pottawatomie and Seminole counties, northwestern Hughes county, southwestern Lincoln county, western Okfuskee county (Figure 1a).

We selected this area based on the location of five high-volume injection wells, two Stasta 1 and 2 wells (shown in red Figure 1b), and three $\sim M_{\mathrm{w}} 5$ events occurred in 2011. There are more than twenty injection wells in our study area (Figure 1) that inject wastewater into the different subsurface targets such as the Woodford formation, Wilcox formation (Simpson group), and the Arbuckle group. The total volume injected down the wells in the area of interest up to the end of Nov 2011 is more than $1.2 \times 10^{7} \mathrm{~m}^{3}$ (OCC) among which five wells account for $93 \%$ of this injected volume (Table 1). Wilzetta located in the northeast of the three major events (Figure 1) supplies 32\% of the total volume. Mazkoori has the minimum distance to the events, and accounts for $8 \%$ of the total injected volume. The other three high-volume wells (Turner, Jesse, Howard) that account for much of the rest of the total volume (Table 1) have distances of 12 to $15 \mathrm{~km}$ southeast of the major events (Figure 1). In this study, we assume that the reported data by OGS and OCC, including the faults geometry and wells location and injection volume, is representative of the in-situ conditions. Wells data (OCC, http://www.occeweb.com/ og/ogdatafiles2.htm) including years of operation (until 2011), the volume of the injected fluid, and the target of injection for the five high-volume injections and two Stasta wells are shown in Table 1.

The stratigraphic section of the study area is shown in Figure 2 (Dycus, 2013). In the model, in addition to the Precambrian basement where most seismic events occurred (more than $3 \mathrm{~km}$ below the surface; Keranen et al., 2013), we include those formations that experienced the most volume of injection. They include the Arbuckle group and the Simpson group. We list the mechanical parameters for different formations in the model in Table 2. It 

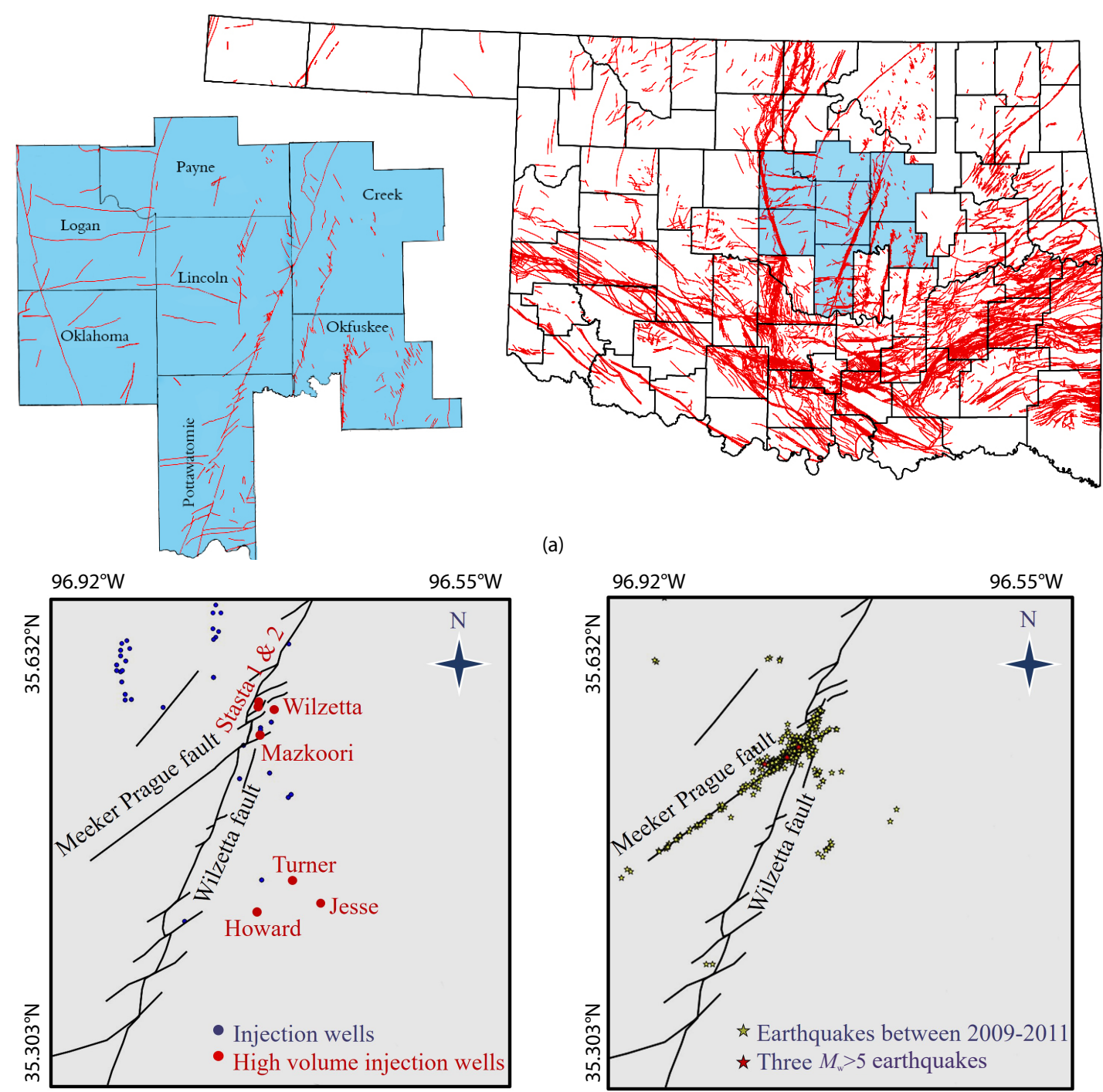

(b)

(a)

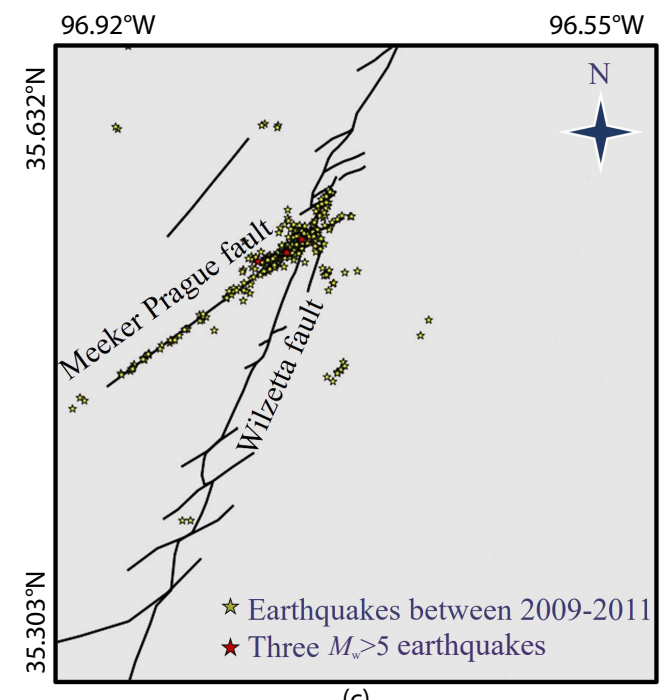

(c)

Figure 1. (a) Oklahoma fault map (Oklahoma Geological Survey (OGS), http://www.ou.edu/ogs/data/fault). The fault traces and the area of interest are shown by red lines and the blue box, respectively. (b) Location of injection wells in the area of interest (Oklahoma Corporation Commission (OCC), http://www.occeweb.com/og/ogdatafiles2.htm) (c) Earthquakes between 2009 and 2011 in the area of interest (OGS, http://www.ou.edu/ogs/research/earthquakes/catalogs).

Table 1. Years of operation (until Nov 2011), the total injected volume of fluid $\left(\times 10^{6} \mathrm{~m}^{3}\right)$, and subsurface target formation for high-volume injection wells and Stasta 1 and 2 wells (OCC, http://www.occeweb.com/og/ogdatafiles2.htm).

\begin{tabular}{cccc}
\hline Well & Years of Operation & Fluid Volume $\left(\times 10^{6} \mathrm{~m}^{3}\right)$ & Subsurface Formation \\
\hline Wilzetta & $1999-2011$ & 3.89 & Wilcox-Arbuckle \\
Mazkoori & $2000-2004$ & 1 & Arbuckle \\
Turner & $2004-2011$ & 2.57 & Wilcox-Arbuckle \\
Jesse & $2003-2011$ & 2.31 & Arbuckle \\
Howard & $2008-2011$ & 1.44 & Arbuckle \\
Stasta-1 & $1993-2011$ & 0.05 & Hunton \\
Stasta-2 & $2006-2011$ & 0.05 & Wilcox-Arbuckle \\
\hline
\end{tabular}

should be noted that the mentioned thickness of the layers in Table 2 represents the average values of the layers (OGS, personal correspondence).

The Precambrian basement is overlain by the Arbuckle and the
Simpson groups, consecutively. The Arbuckle group predominantly consists of limestone and dolomite, is a basal sedimentary stratum, and has been the main target for most Class II UIC SWD volumes in Oklahoma (Murray -and Holland, 2014). The geomech- 


\begin{tabular}{|c|c|c|c|c|}
\hline System & Series & Group & Formation & Subsurface Name \\
\hline \multirow{34}{*}{ 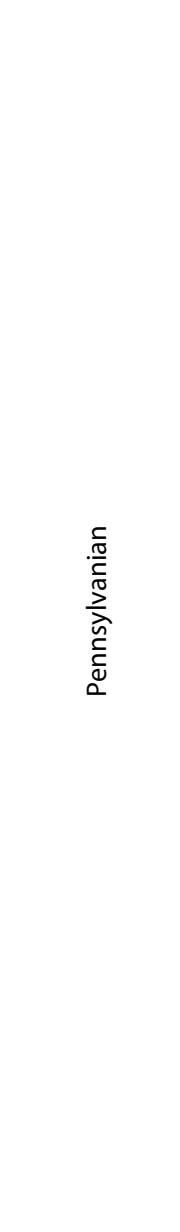 } & \multirow{6}{*}{ Virgillian } & \multirow{2}{*}{ Wabanusee } & Vanoss & Emporia \\
\hline & & & \multirow{2}{*}{ Ada } & Pawhuska \\
\hline & & \multirow{2}{*}{ Shawnee } & & Hoover \\
\hline & & & \multirow{2}{*}{ Vamoosa } & Oread \\
\hline & & \multirow{2}{*}{ Douglas } & & Endicott \\
\hline & & & Tallant & Tonkawa \\
\hline & \multirow{13}{*}{ Missourian } & \multirow{5}{*}{ Ochelata } & Barnsdall & Okesa \\
\hline & & & Wann & Perry Gas \\
\hline & & & Iola & Avant \\
\hline & & & Chanute & Osage Layton \\
\hline & & & cnanute & Cottage Grove \\
\hline & & \multirow{8}{*}{ Skiatook } & Dewey & Dewey \\
\hline & & & Nellie Bly & \\
\hline & & & \multirow{2}{*}{ Hogshooter } & Hogshooter \\
\hline & & & & Layton \\
\hline & & & Coffeyville & \\
\hline & & & \multirow{2}{*}{ Checkerboard } & Checkerboard \\
\hline & & & & Cleveland \\
\hline & & & Seminole & \\
\hline & \multirow{15}{*}{$\begin{array}{c}\text { Des } \\
\text { Moinesian }\end{array}$} & \multirow{6}{*}{ Marmaton } & Holdenville-Nowata & \\
\hline & & & Oolagah & Big Lime \\
\hline & & & Labette & \\
\hline & & & \multirow{3}{*}{ Fort Scott } & Oswego \\
\hline & & & & Little Osage \\
\hline & & & & Excello \\
\hline & & \multirow{3}{*}{ Cabaniss } & & Prue \\
\hline & & & Senora & Verdigris \\
\hline & & & & Skinner \\
\hline & & \multirow{6}{*}{ Krebs } & & Pink \\
\hline & & & & Redfork \\
\hline & & & Boggy & Inola \\
\hline & & & & Bartlesville \\
\hline & & & Savanna & Brown \\
\hline & & & Mc Alester & Booch \\
\hline \multirow{3}{*}{ 'Mississippian } & Chesterian & & Chester & Caney \\
\hline & Maramecian & & Moorfield & Mayes \\
\hline & Osagean & & Osage & Osage \\
\hline Devonian & Chattanoogian & & Chattanooga & Woodford \\
\hline Silurian & Hunton & & Hunton & Hunton \\
\hline \multirow{7}{*}{ Ordovician } & Cincinnatian & Richmond & Sylvan & Sylvan \\
\hline & \multirow{5}{*}{ Champlainian } & Mohawkian & Viola & Vioal \\
\hline & & \multirow{4}{*}{ Simpson } & Bromide & Wilcox \\
\hline & & & Tulip Creek & Tulip Creek \\
\hline & & & McLish & \\
\hline & & & Oil Creek & \\
\hline & Canadian & \multirow{2}{*}{ Arbuckle } & \multirow{2}{*}{ Arbuckle } & Arbuckle \\
\hline Cambrian & Croixan & & & Arbuckle \\
\hline
\end{tabular}

Figure 2. Stratigraphic section of the study area above the Precambrian basement (Dycus, 2013).

Table 2. Rock mechanical and hydraulic properties used in the simulations. ((1) Yu, 2017; (2) Carell and Kellar, 2014; (3) Cappa, 2009; (4) Chester et al., 1993; (5) Kolawole et al., 2019).

\begin{tabular}{|c|c|c|c|c|c|}
\hline & Lower Simpson & Simpson & Arbuckle Group & Basement & Fault damage zone \\
\hline Horizontal permeability (mD) & $6.7 \times 10^{-4}(2)$ & $6.7 \times 10^{-4}(2)$ & $10-50^{(1,2)}$ & $6.7 \times 10^{-4}(1,2)$ & $10-50(3)$ \\
\hline Porosity, $\phi$ & $0.13^{(2)}$ & $0.13^{(2)}$ & $0.1^{(1,2)}$ & $0.01^{(2)}$ & $0.1^{(3)}$ \\
\hline Young's modulus $E$ (GPa) & $45^{(4)}$ & $45^{(4)}$ & $76^{(1)}$ & $80^{(1)}$ & $25^{(3)}$ \\
\hline Friction angle, $\varphi\left(^{\circ}\right)$ & $31^{(4)}$ & $31^{(4)}$ & $30^{(1)}$ & $35.5^{(1,5)}$ & $25^{(3)}$ \\
\hline Thickness (m) & 160 & 200 & 750 & 4000 & \\
\hline
\end{tabular}


anical properties of the Arbuckle group of rocks can be found in Yu WQ and Ghassemi (2017) and Yu WQ (2017). An extensive joint system formed by the basement tectonics (Walters, 1958; Carell and Kellar, 2014) makes the Arbuckle group porous and permeable enough to easily accept the injection of wastewater (under the hydrostatic head). However, the injected water does not appear to remain within Arbuckle and finds its way into basement rocks via natural fractures. The pressurization and stress redistribution within the basement can lead to fault reactivation and increased seismicity. The Simpson Group is made up of sands, carbonates, and shales. It has been a great producer of oil and gas in Oklahoma (Statler, 1965). The lower section of Simpson group overlies the Arbuckle group and is characterized by a thick shaley zone. This shaley layer seals the Arbuckle group from the top. In this study, we refer to this zone as the lower Simpson.

Previous reports state that, the Arbuckle group is underpressured, and has a hydrostatic pressure of $\sim 9 \mathrm{MPa} / \mathrm{km}$ (Carell and Kellar, 2014; Nelson et al., 2015). Available data (Dart, 1990) shows a wide range for the direction of the maximum principal stress $\left(S_{H, \max }\right)$. For example, Von Schönfeldt (1973) and Hooker and Johnson (1969) reported $\mathrm{N} 65^{\circ} \mathrm{E}$ and $\mathrm{N} 94^{\circ} \mathrm{E}$ for the $S_{H, \max }$ azimuth using hydraulic fracturing and overcoring methods, respectively. Alt and Zoback's (2017) more recent data indicate a $S_{H, \max }$ azimuth of $\mathrm{N} 85^{\circ}\left( \pm 5^{\circ}\right) \mathrm{E}$. In this study, we assume the orientation of the maximum principal stress as $\mathrm{N} 83^{\circ} \mathrm{E}$, which is in the range of all available data (Alt and Zoback, 2014). The gradients of the maximum and minimum horizontal stresses, and overburden gradients are

$$
\frac{\partial S_{H, \max }}{\partial z}=30 \frac{\mathrm{MPa}}{\mathrm{km}}, \frac{\partial S_{h, \text { min }}}{\partial z}=15 \frac{\mathrm{MPa}}{\mathrm{km}}, \frac{\partial S_{\text {vertical }}}{\partial z}=25 \frac{\mathrm{MPa}}{\mathrm{km}},
$$

respectively ( Hair, 2012). We consider only the five high-volume wells (Table 1) in our model. All of these wells are located on the eastern side of the Wilzetta fault zone (Figure 1b). Wilzetta, Mazkoori, and Stasta wells are within a distance of less than $500 \mathrm{~m}$ to the Wilzetta fault. In contrast, Turner, Jesse, and Howard wells are farther (more than $5 \mathrm{~km}$ ). Therefore, the former wells potentially have more effect on the Wilzetta fault. In the OCC database, some reported monthly wellhead pressures do not have a consistent trend. At times the wellhead pressure is reported as zero, and then increases again. It is unclear if this has a physical reason (for example, propagation of a fracture from the well) or just a missing data point. In these situations, we assume the pressure to be equal to the reading of the closest previous months.

The subsurface permeability distribution is an essential aspect of the problem, particularly in the fault zones. In the absence of hydromechanical properties of the Wilzetta fault zone and different subsurface formations, we consider different possible fault architectures. In many geological settings, fault zones are described as meters-to-kilometers thick zones which have a complex architecture, and consist of (1) one or numerous core zones where most displacements take place, and (2) a fractured damage zone with a width of less than $1 \mathrm{~m}$ to several hundred meters (Chester et al., 1993; Caine et al., 1996).

The fault core may include different structures such as slip surfaces, gouge, breccias, cataclasites, clay smears, and geochemically altered rock bodies (Chester and Logan, 1986; Antonellini and
Aydin 1994). The damage zone surrounded by the host rock is formed by the growth of the fault zone and may consist of subsidiary faults, veins, joints, stylolites, cleavage, and folds (Caine et al., 1996). Typically, these fault components and the host rock show obvious differences in hydromechanical properties. Fault zone architecture and its component dimensions are highly dependent on the type and initial condition of the rocks. For example, the low and high-porosity layers show two types of deformation which result in different variations of the porosity toward the fault core. In high-porosity layers, grains can move and slide more freely, leading to the accommodation of the deformation at the grain scale and a decrease in porosity toward the fault core. In contrast, in less porous layers, well-cemented grains, and the rocks are more brittle, so the deformation includes the increase of fracture porosity (Rinaldi et al., 2014). In this study, both possible fault zone architectures are considered: (1) a fault zone (having a core zone and a fractured damage zone), and (2) a simple plane wherein displacements occurred (without any hydromechanical properties difference between the fault zones and the host rock).

Additionally, there are no observation points to measure the pore pressure changes in the area of interest. Instead, we use the available wellhead pressure (plus the hydrostatic column) to estimate the target layer pressure. This pressure is not always representative of the reservoir pressure. However, as mentioned before, at the time of injection operation, it is reasonable to consider nearwellbore pressure to be equal to the wellhead pressure plus the hydrostatic column in the well. Therefore, in this article, the pressure buildup calculated by the numerical model may not reflect what exactly happened during the injection operation in reality.

\subsection{Numerical Model}

We conducted with the FLAC3D software (Itasca Consulting Group Inc, 2012) considering both fluid flow and coupled stress calculations. The poromechanical equations are as follows (for an isothermal process) (Cheng, 2016).

\section{Fluid Transport (Darcy Law)}

$$
\boldsymbol{q}^{\mathrm{F}}=-k \nabla\left(P_{\mathrm{p}}-\rho_{\mathrm{f}} \boldsymbol{g} \cdot \boldsymbol{x}\right),
$$

where $k$ is the fluid mobility coefficient $\left(k=\kappa / \mu_{\mathrm{f}}\right.$, where $\kappa$ is the intrinsic permeability, and $\mu_{\mathrm{f}}$ is the fluid dynamic viscosity, and $\rho_{\mathrm{f}}$ is fluid density).

\section{Fluid Mass Balance}

$$
\frac{\partial P_{\mathrm{p}}}{\partial t}=-M\left[\nabla \cdot q^{\mathrm{F}}+a \frac{\partial\left(\varepsilon_{v}\right)}{\partial t}\right]
$$

where $P_{\mathrm{p}}$ is fluid pressure, $M$ is the Biot's modulus, $\varepsilon_{v}$ is the volumetric strain.

The mechanical constitutive relations for elastic material are:

$$
\frac{\partial \sigma_{i j}}{\partial t}+a \frac{\partial P_{f}}{\partial t} \delta_{i j}=2 G\left(\frac{\partial \varepsilon_{i j}}{\partial t}\right)+\left(K-\frac{2 G}{3}\right)\left(\frac{\partial \varepsilon_{k k}}{\partial t}\right) \delta_{i j},
$$

where $\sigma_{i j}$ and $\varepsilon_{i j}$ are total stresses and strains, $a$ is Biot's effective stress coefficient, $K$ and $G$ are bulk and shear modulus, and $\delta_{i j}$ is Kronecker delta. 


\section{Simulation Set-up}

In building the simulations, we consider the real topography and the spatial geometry of the faults, and incorporate them in the determination of the initial state. The rock layers are assigned the Mohr-Coulomb plasticity constitutive model. There are generally three approaches to simulate fault hydromechanical behavior: (1) zero-thickness mechanical interfaces, (2) an equivalent continuum representation using solid elements, and (3) a combination of solid elements, and ubiquitous-joints oriented as weak planes (Rutqvist et al., 2002; Cappa, 2009; Gan Q and Elsworth, 2014; Gao Q and Ghassemi, 2020). In this study, we use the zerothickness mechanical interface to model the fault behavior. Interface elements are attached to an element surface. We calculate absolute normal penetration and the relative shear velocity at each time step for each interface node and its contacting target face. Then, by applying the interface constitutive model (Coulomb shear-strength criterion), these values are used to calculate normal and shear-force vectors. We assume the fault core as a plane across which fluid may flow in the normal direction (1D flow).

We construct a simulation domain that is large enough to encompass all the injection wells in our study area. To prevent any boundary effect, we calculate the diffusivity and accordingly set the dimensions of the domain. Using the injection time $\left(t_{\text {inj }}=12\right.$ years and 9 months) and other parameters from Table 1, the min- imum distance from each well to the domain boundary can be calculated. For example, it is calculated in cases 1 and 2 of scenarios 1 to 3 as:

$$
L=\sqrt{c t_{\text {inj }}}=\sqrt{0.27 \times 4.1 \times 10^{8}}=10457 \mathrm{~m} \approx 10.5 \mathrm{~km},
$$

where $c$ is the "diffusivity" (Cheng AHD, 2016), $c=\frac{k}{S}$ with

$$
S=\frac{1}{M}+\frac{a^{2}}{K+\frac{4 G}{3}} \approx \frac{\phi}{K_{f}}+\frac{1}{K+\frac{4 G}{3}},
$$

where $M, K_{f}, \phi, S$ are Biot's modulus, fluid bulk modulus, porosity, elastic storage, respectively. In Equation (4), we assume that the grain compressibility is negligible $(a=1)$.

The domain is more than $33.6 \mathrm{~km}$ in the east-west, and $36.6 \mathrm{~km}$ in the north-south directions, and includes the Simpson group, the Arbuckle group, and the Precambrian basement. The thickness of our model is $4.7 \mathrm{~km}$, and the top and the bottom of the model are located at depths of $0.8 \mathrm{~km}$ and $5.5 \mathrm{~km}$. We define faults extending up from the basement at depth of $\sim 5 \mathrm{~km}$ through the Arbuckle group (OGS; Keranen et al., 2013; Kolawole et al., 2019, 2020). Figure 3 shows the dimension of the domain, the geometry of the faults, and the location of seven injection wells inserted into the model.

The change of pore pressure and the induced stresses are calcu-
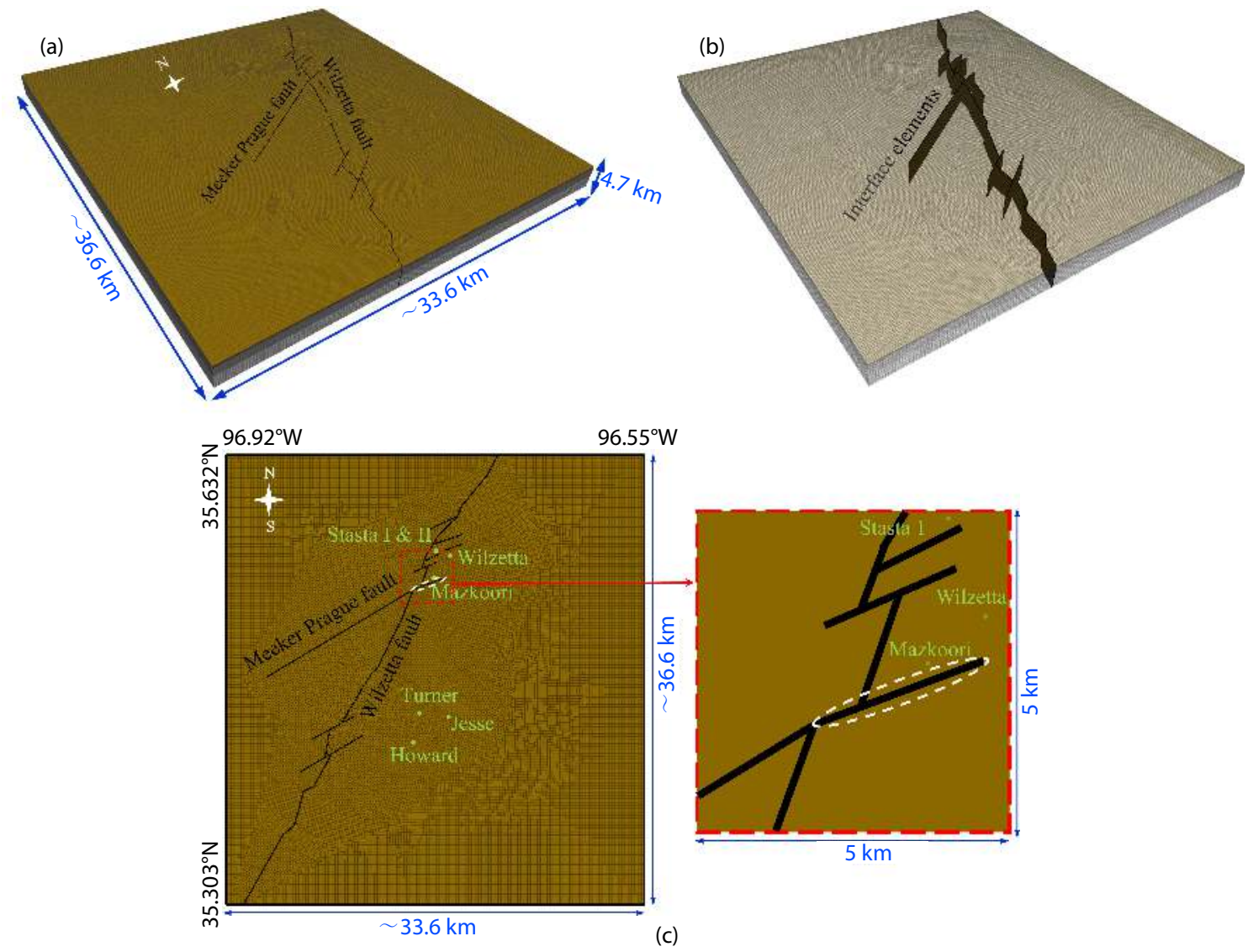

Figure 3. (a) The 3D view of the model and the location of the faults; (b) The sketch of interface elements representative of faults; (c) The plan of the domain and location of the faults and injection wells. Since most events (especially $\sim M_{\mathrm{w}}=5$ events, Figure 1 ) were located on the splay branch of the Wilzetta fault (shown by the dashed white line) and the Meeker Prague fault, we pay special attention to this region. 
lated in our model. Wilzetta, Turner, and Stasta-2 wells inject wastewater into both the Wilcox and Arbuckle groups. In contrast, the other wells inject only into the Arbuckle group (Table 1). The only well that injects directly into the Hunton layer is Stasta-1 well. The Hunton group contains oil in compartments near the Stasta wells (Way, 1983), suggesting entrapment of hydrocarbons (preventing fluid migration to other layers). Although these reservoir compartments in the Hunton group suggest no hydraulic communication between the isolated compartments and the surrounding rocks (both within the Hunton group and adjacent layers), some authors have proposed there may be hydraulic communication between the Arbuckle group and the Precambrian basement (Keranen et al., 2013). In the absence of concrete data, we assume that the Hunton group is isolated, and does not have any hydraulic communication with other layers. It should be noted that the Oklahoma Corporation Commission (OCC, http://www.occeweb.com/og/ogdatafiles2.htm) reports the monthly injection volume and the wellhead pressure of all wells. The values of wellhead pressure are reported constant during the month and reflect values of pressure only during pumping. Reservoir pressure near the wellbore is set equal to this value during the pumping and dissipates after injection stops. Over many cycles, the pressure near the wellbore spikes and drops, and after a while, the wellhead pressure would normally increase unless the fluid readily finds open/low-pressure zones. Due to lack of data, we apply a continuous injection in our simulations. Therefore, we do not capture the detailed potential pore pressure fluctuating near the wellbore. Instead, we observe a constant increase of pore pressure, which is dependent on the injection rate and transmissivity of the target layer.

Additionally, there are no observation points to measure the pore pressure changes in the area of interest. Instead, we use the available wellhead pressure (plus the hydrostatic column) to estimate the target layer pressure. This pressure is not always representative of the reservoir pressure. However, as mentioned before, at the time of injection operation, it is reasonable to consider nearwellbore pressure to be equal to the wellhead pressure plus the hydrostatic column in the well. Therefore, in this article, the pressure buildup calculated by the numerical model may not reflect what exactly happened during the injection operation in reality.

Using the well data (the total injection volume, perforation depth, and injection target layers) and transmissivity of each layer, the volume of injection into each layer can be specified. The transmissivity $(T)$ for horizontal flow in a layer with a saturated thickness $h$, and horizontal hydraulic conductivity $K_{\mathrm{h}}$ is

$$
T=K_{\mathrm{h}} h \text {. }
$$

Therefore, if a total rate of $q_{\mathrm{t}}$ (the total volume divided by injection time) is injected into $n$ different layers, the rate into the $i$-th layer is obtained by (continuity, Bear, 2013):

$$
q_{i}=\frac{K_{i} h_{i}}{\sum_{i=1}^{n} K_{i} h_{i}} q_{\mathrm{t}} .
$$

Knowing the monthly total injection volume, and using perforation intervals for each well (OCC), and also assuming that the injection operation was performed continuously, we obtain the monthly volume of injection for each group. For example, the injection volume rate of each group by Wilzetta well, which injects into the Arbuckle and the Simpson groups, can be calculated by the following equation

$$
q_{\text {Arbuckle }}=\frac{K_{\text {Arbuckle }} h_{\text {Arbuckle }}}{K_{\text {Wilcox }} h_{\text {Wilcox }}+K_{\text {Arbuckle }} h_{\text {Arbuckle }}} q_{t}
$$

where $q_{\mathrm{t}}$ is the total injection rate.

Due to the limited information on the geomechanical and hydraulic properties of the area, we make several assumptions and consider different hydraulic relationships between the geological layers and fault zone. We define three major scenarios (Table 3) that are subdivided into cases. In each case, we make some assumptions and study the effect of injection on Wilzetta and

Table 3. Different scenarios and cases in the model.

Scenario 1: No hydraulic communication between geological layers.

Case 1: Faults are impermeable, $K_{\text {Simpson }}=1 \mathrm{mD}, K_{\text {Arbuckle }}=10 \mathrm{mD}$

Case 2: Faults are permeable, $K_{\text {Simpson }}=1 \mathrm{mD}, K_{\text {Arbuckle }}=10 \mathrm{mD}$

Case 3: Faults are impermeable, $K_{\text {simpson }}=1 \mathrm{mD}, K_{\text {Arbuckle }}=100 \mathrm{mD}$

Case 4: Faults are permeable, $K_{\text {Simpson }}=1 \mathrm{mD}, K_{\text {Arbuckle }}=100 \mathrm{mD}$

Scenario 2: Hydraulic communication between geological layers by the fault damage zone.

Case 1: Faults are impermeable, $K_{\text {Simpson }}=1 \mathrm{mD}, K_{\text {fault }}=10 \mathrm{mD}, K_{\text {Arbuckle }}=10 \mathrm{mD}$

Case 2: Faults are permeable, $K_{\text {Simpson }}=1 \mathrm{mD}, K_{\text {fault }}=10 \mathrm{mD}, K_{\text {Arbuckle }}=10 \mathrm{mD}$

Case 3: Faults are impermeable, $k_{\text {simpson }}=1 \mathrm{mD}, K_{\text {fault }}=100 \mathrm{mD}, K_{\text {Arbuckle }}=10 \mathrm{mD}$

Case 4: Faults are permeable, $K_{\text {Simpson }}=1 \mathrm{mD}, K_{\text {fault }}=100 \mathrm{mD}, K_{\text {Arbuckle }}=10 \mathrm{mD}$

Case 5: Faults are impermeable, hydraulic communication between geological layers by the fault damage zone, and there is a permeability anisotropy (vertical to horizontal direction ratio of 0.5 ). $K_{\mathrm{h}, \text { Simpson }}=1 \mathrm{mD}, K_{\text {fault }}=10 \mathrm{mD}, K_{\mathrm{h} \text {,Arbuckle }}=10 \mathrm{mD}$

Case 6: Faults are impermeable, hydraulic communication between geological layers by the fault damage zone exists only on a portion and some splay branches of the Wilzetta fault (constrained by the white dashed line in Figure $5 \mathrm{a}$ ), $K_{\text {simpson }}=1 \mathrm{mD}, K_{\text {fault }}=10 \mathrm{mD}, K_{\text {Arbuckle }}=10 \mathrm{mD}$ Case 7: Faults are impermeable, hydraulic communication between geological layers by the fault damage zone exists only on a splay branch of the Wilzetta fault (constrained by the white dashed line in Figure $5 b$ ), $K_{\text {Simpson }}=1 \mathrm{mD}, K_{\text {fault }}=10 \mathrm{mD}, K_{\text {Arbuckle }}=10 \mathrm{mD}$

Scenario 3: There is only a damage zone around a part of the Wilzetta fault, and there is a bounded volume in the Arbuckle group into which Wilzetta and Mazkoori wells inject.

Faults are impermeable, $K_{\text {Simpson }}=1 \mathrm{mD}, K_{\text {fault }}=10 \mathrm{mD}, K_{\text {Arbuckle }}=10 \mathrm{mD}$ 


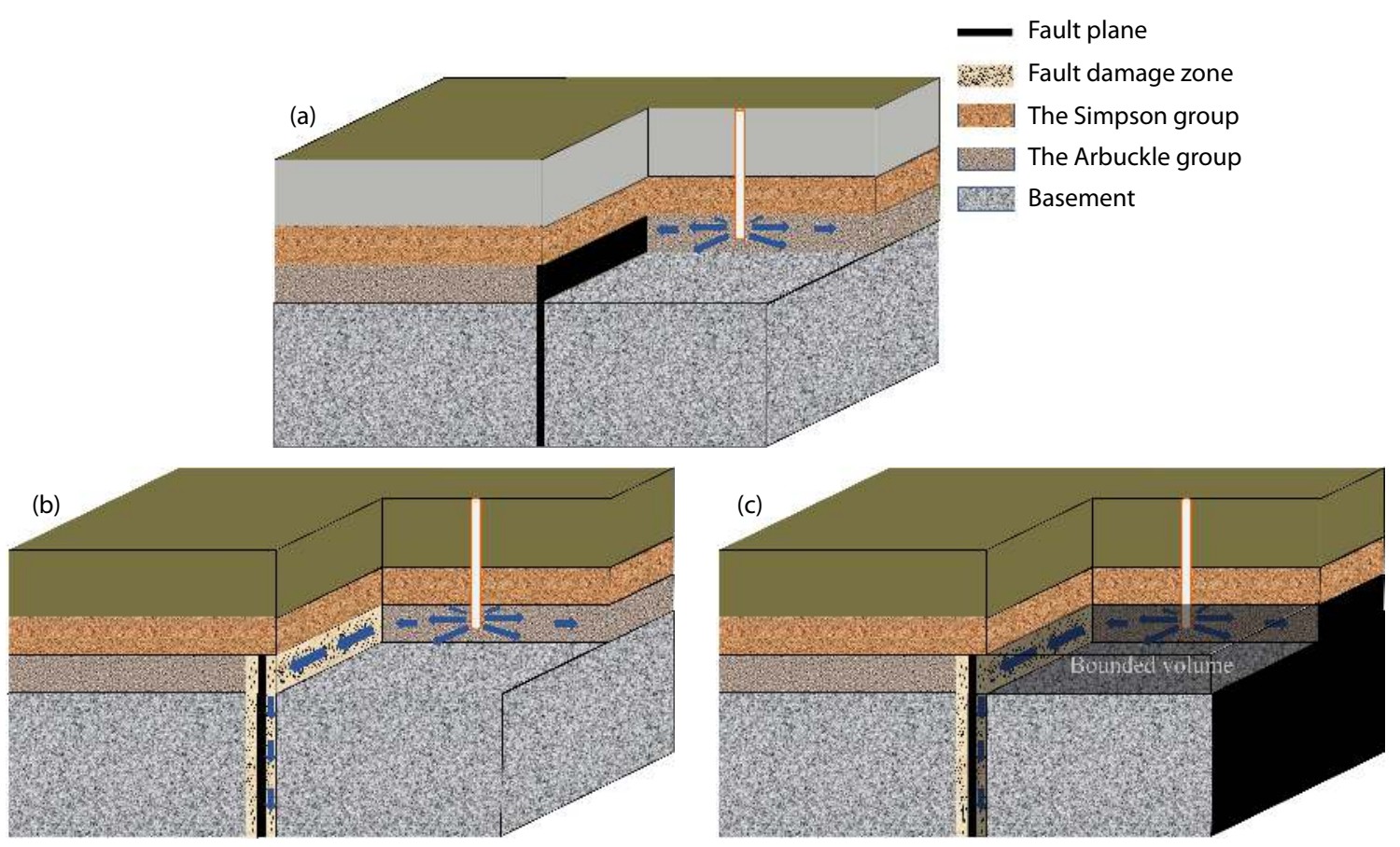

Figure 4. Schematic for (a) scenario 1: there is no communication between the Arbuckle group and the basement, and fluid diffuses into the Arbuckle group in semi-restricted and infinitely open volume in cases with impermeable and permeable, respectively; (b) scenario 2: fluid penetrates the deeper depths through the damage zone; (c) scenario 3: there is only a damage zone around a part of the Wilzetta fault, and there is a bounded volume in Arbuckle group in which wastewater accumulated resulting in pore pressure elevation.
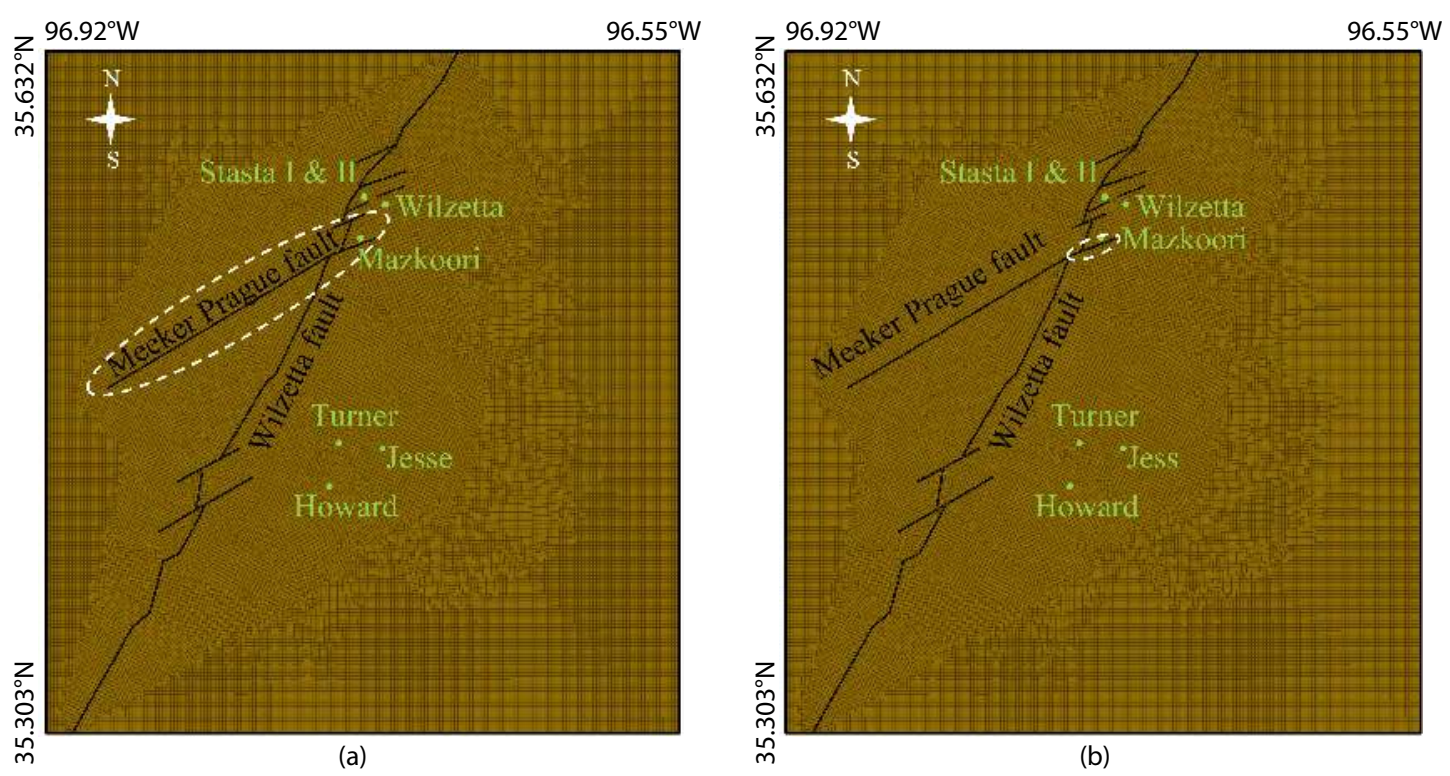

Figure 5. The damage zone exists only in a portion and some splay branches of the Wilzetta Fault in (a) case 6 and (b) case 7 of scenario 2 . The white dashed line shows the portion and splay branches of the Wilzetta faults for which the damage zone is defined in the model. Green dots show the locations of high-volume injection wells.

Meeker Prague faults. For each scenario, we defined different cases where we assigned different properties, such as the hydraulic properties of fault zones.

In the first scenario, we assume no hydraulic communication between different geological units and groups (Figure 4a). For example, we assume that the Arbuckle group is sealed, and there is no hydraulic connection with the Simpson group and the base- ment from the top and the bottom, respectively. Both lower Simpson and the basement have very low matrix permeability. In this scenario, the possibility of fluid flow through fractures in the basement is neglected. Therefore, the entire injected water diffuses into the target layer, and does not escape to the upper and lower adjacent layers. In the second scenario (Figure 4b), we consider the possibility of hydraulic communication between differ- 
ent geological layers. More specifically, this communication is through the fractures around the fault plane (i.e., the damage zone) through which fluid penetrates the deep crystalline basement. Since most events (especially the foreshock with $M_{\mathrm{w}} 4.8$, Figure 1) were located on the Wilzetta fault shown by the white dashed line in Figure 3, we pay special attention to this area. In scenario 3 , we assume that the damage zone is located only around the Wilzetta fault (shown by the white dashed line in Figure 3c), and there is a bounded volume in the Arbuckle group into which Wilzetta and Mazkoori wells inject. Note that we make this assumption because there used to be an oil field in the area (Keranen et al., 2013; OCC; http://www.ogs.ou.edu/fossilfuels/ MAPS/GM-36.pdf).

\section{Simulation Results}

\subsection{Scenario 1 - Cases 1 and 2: Impermeable and Permeable Faults with Low Arbuckle Permeability}

Using Equation (7), for cases 1 and 2 of this scenario more than $99 \%$ of the total injection volume goes into the Arbuckle group.

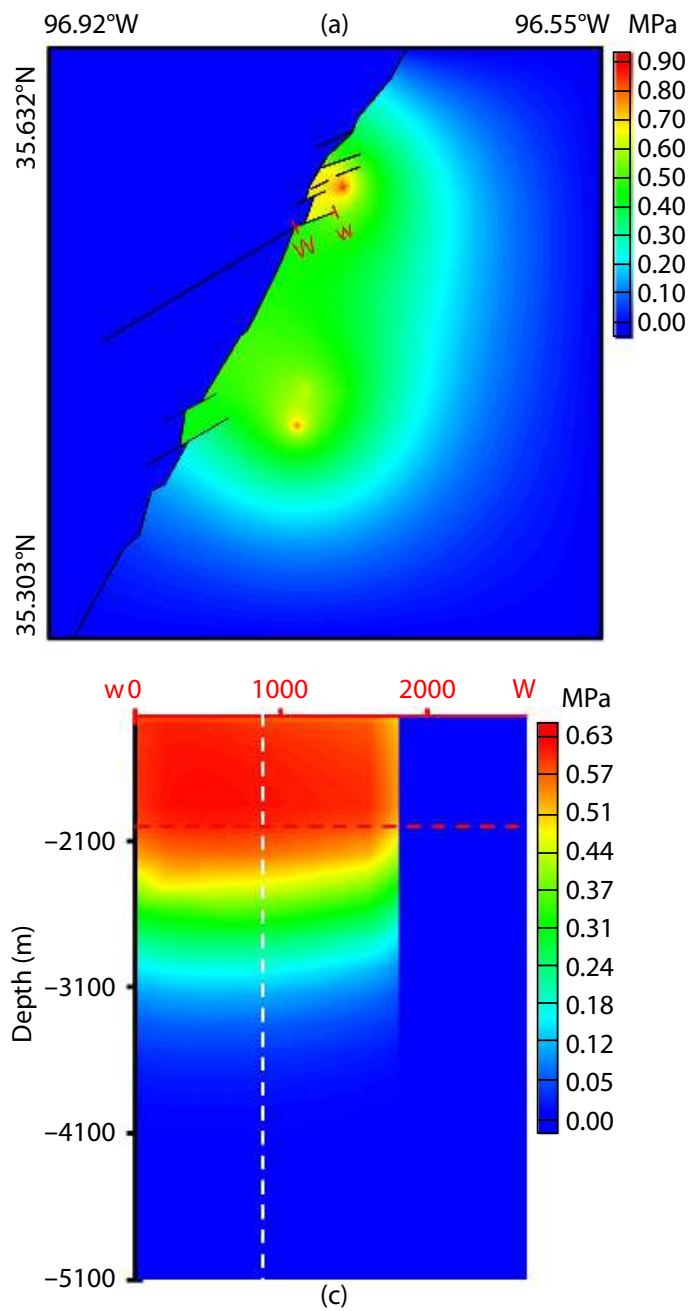

Figure 6 shows the change in pore pressure of the Arbuckle group (at a depth of $1600 \mathrm{~m}$, i.e., almost the middle depth of the Arbuckle group) in Nov 2011 (after 12 years and 10 months of injection and at the time of main foreshocks) after injection of 11.2 million $\mathrm{m}^{3}$ of wastewater in six wells for cases 1 and 2, respectively. In both cases 1 and 2, the injection induces the maximum pressure change of $\sim 0.8-0.9 \mathrm{MPa}$ near the Howard well. In case 1, there is a maximum pore pressure increase of $0.9 \mathrm{MPa}$ around the Wilzetta well, and an increase of 0.3-0.6 MPa over a relatively large area $(7 \mathrm{~km} \times 17 \mathrm{~km}$ ) between the northern and southern wells in the Arbuckle group at a depth of $1600 \mathrm{~m}$. Due to the cross-fault flow in case 2 , the pore pressure is affected over a larger area, and the overall values of the excess pore pressure (the average of $0.2-$ $0.3 \mathrm{MPa}$ ) are less than those of case 1. The pore pressure change on the splay branch of the Wilzetta fault plane (W-W) in Nov 2011 (after 12 years of injection) for cases 1 and 2 of scenario 1 are shown in Figures $6 c$ and $d$, respectively. The maximum values of the pressure elevation on the fault plane are 0.63 and $0.33 \mathrm{MPa}$ in cases 1 and 2, respectively. This is because, in case 1, we assume that faults are impermeable, which prevents fluid flow into the

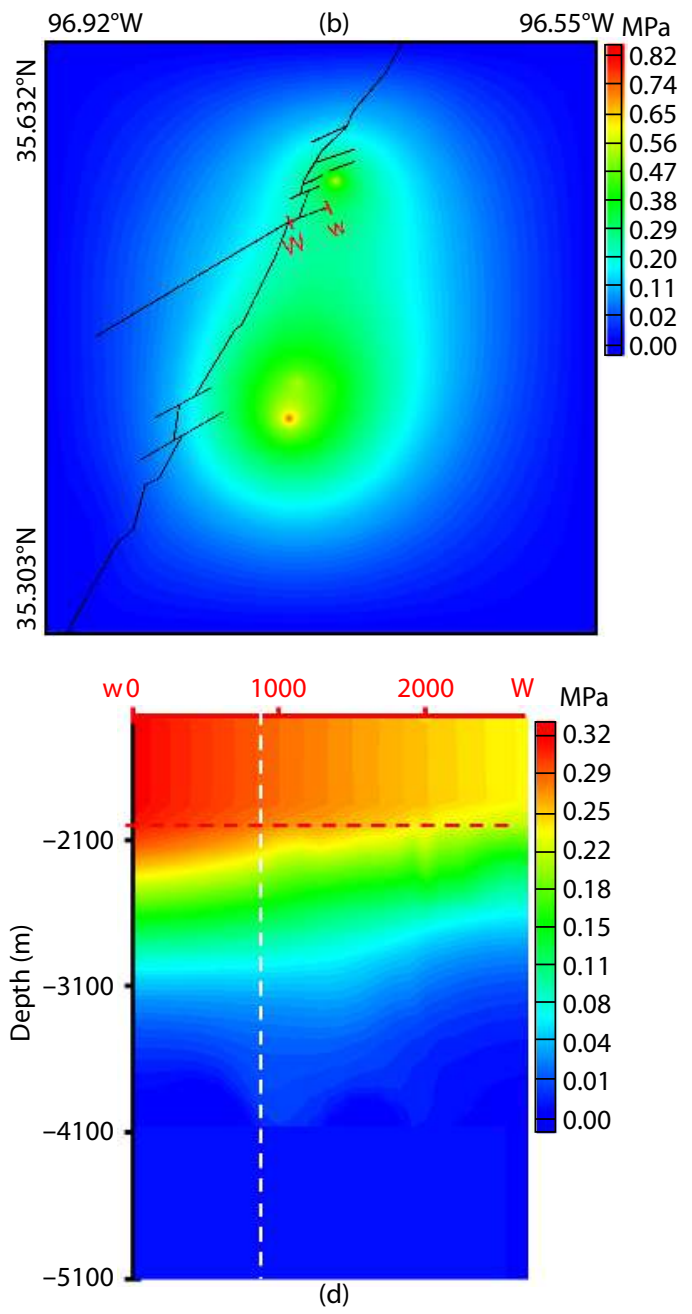

Figure 6. Scenario 1: The change of pore pressure (MPa) in Arbuckle group at a depth of $1600 \mathrm{~m}$ in Nov 2011 (after 12 years and $10 \mathrm{months}$ of injection) for (a) case 1, and (b) case 2. The pore pressure change on the splay branch of the Wilzetta fault plane along the W-w for (c) case 1 and (d) case 2. The Arbuckle group's top and lower boundaries are shown by the red solid and dashed lines, respectively. The white dashed line is the vertical line on the fault plane that has the shortest distance to the Mazkoori well. 


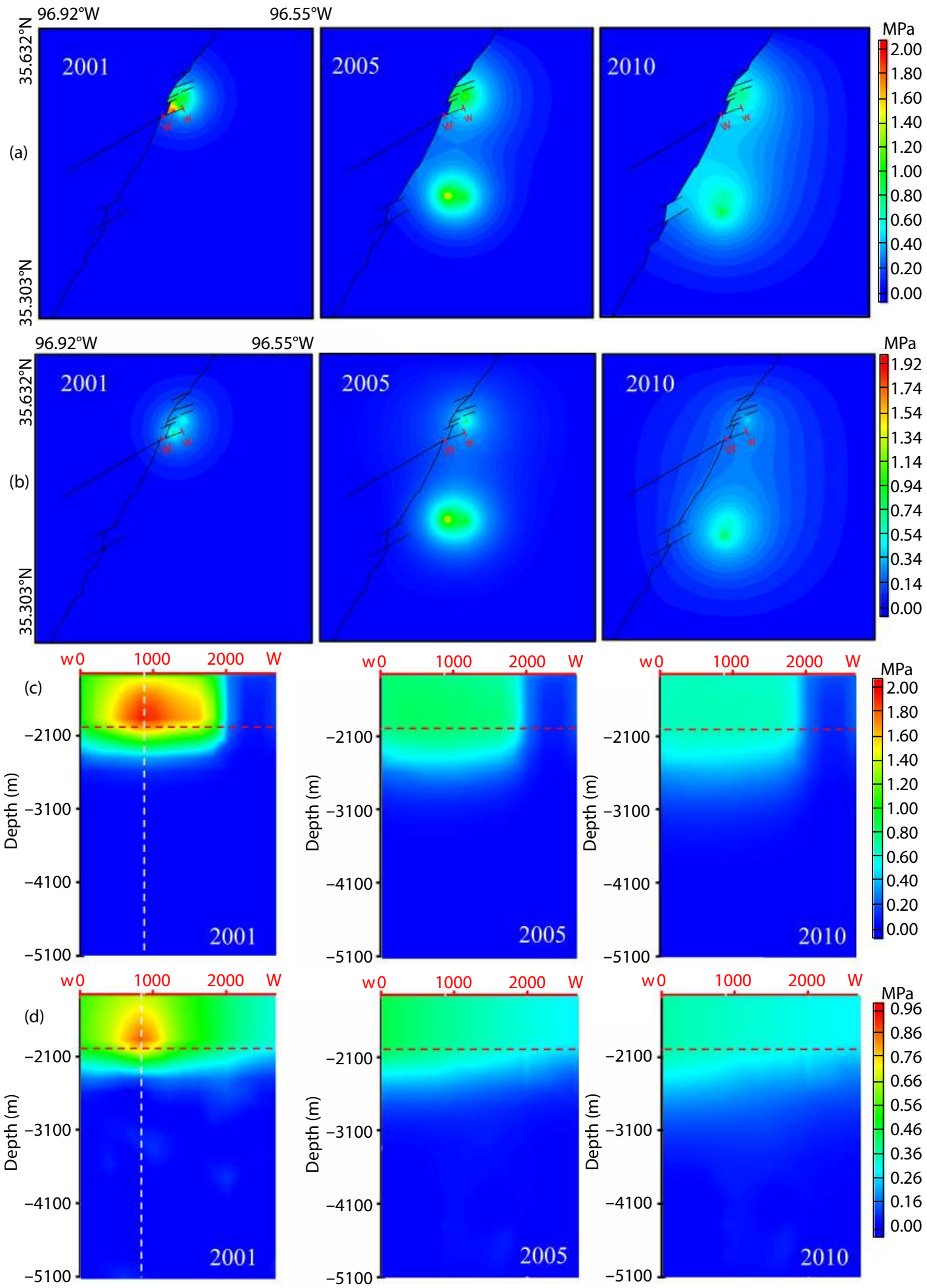

Figure 7. Scenario 1: The pore pressure change (MPa) in the Arbuckle group at depth of a $1600 \mathrm{~m}$ at the end of 2001 (left), 2005 (middle), and 2010 (right) for a) case 1 and b) case 2. The pore pressure change (MPa) on the splay branch of the Wilzetta fault plane along the cross-section W-w at the end of 2001 (left), 2005 (middle), and 2010 (right) for c) case 1 and d) case 2. The Arbuckle group's top and lower boundaries are shown by the red solid and dashed lines, respectively. The white dashed line is the vertical line on the fault plane that has the shortest distance to the Mazkoori well.

target layers, and consequently a higher pore pressure buildup. In this scenario, since there is no fluid path (e.g., fault damage zone) between the target layers and the basement, the fluid only penetrates the basement to a depth of $3.4 \mathrm{~km}$, and therefore without changing the pore pressure in the location of the main events.

Figure $7 \mathrm{a}$ and $\mathrm{b}$ compare the injection-induced pore pressures at the end of 2001, 2005, and 2010 at depth of $1600 \mathrm{~m}$ for cases 1 
and 2 of scenario 1, respectively. Notice that the pattern and the values of the pressure elevation are not constant during the years of injection due to the variation of the well's operational times and different injection volumes. For example, the Mazkoori well started injection in 2000 and ended in 2004. Since the Mazkoori is the shortest distance from the Wilzzeta fault, it is expected to have the greatest effect on the pore pressure of the Wilzetta fault plane along the section $\mathrm{W}-\mathrm{w}$. Figure $7 \mathrm{c}$ and $\mathrm{d}$ show the change of pore pressure on the splay branch of the Wilzetta fault plane along the section $\mathrm{W}-\mathrm{W}$ in 2001, 2005, and 2010 for cases 1 and 2, respectively. As expected, in case 1, the operation of Mazkoori well and the impermeable nature of the faults can cause the maximum pressure buildup of $2 \mathrm{MPa}$ along the $\mathrm{W}-\mathrm{W}$ fault plane, while in case 2 , permeable faults result in lower pressure of $1 \mathrm{MPa}$. After 2005, when injection into the Mazkoori well ended, the induced pore pressure on the section $\mathrm{W}-\mathrm{W}$ (Figure 7) is reduced, and after a couple of months remains at an almost constant value of 0.3 MPa until the end of the simulation (Nov 2011).

As mentioned before, the injection causes a change of total stresses. For example, Figure 8 shows the change of the total horizontal stress components $\sigma_{x x}$ and $\sigma_{y y}$ caused by injection in scenario 1 after 12 years and 10 months of injection (in Nov 2011), respectively. Notice that, based on the pore pressure and poroelast- ic properties, the induced total $\Delta \sigma_{x x}$ and $\Delta \sigma_{y y}$ are $0.45 \mathrm{MPa}$ and $0.38 \mathrm{MPa}$ in cases 1 and 2, respectively. To study the stability of faults, different values of coefficient of friction in the range proposed by Byerlee (1978; under high normal stress, the range is 0.6 to 1 corresponding to a friction angle of $31^{\circ}$ to $45^{\circ}$ ) are assigned for the faults in the model to study if the induced changes in pore pressure and total stresses are enough to cause slip on faults.

Figure 9 shows the different values of the shear stress and the shear strength (CFS) of the three points at depths of $1600 \mathrm{~m}, 2050 \mathrm{~m}$, and $4500 \mathrm{~m}$ corresponding to the middle of the Arbuckle group, the shallow basement, and the deep basement along the vertical dashed white line (Figure 6 and Figure 7; the vertical line on the fault plane that has the shortest distance to the Mazkoori well) on the splay branch of the Wilzetta fault plane along the cross-section W-W (Figure 7) during the history of injection (for case 1 of scenario 1). We find that the variation trend of CFS is similar for all three points at different depths. Figure 9a reveals that for $\mu=0.66$, the CFS at depth of $1600 \mathrm{~m}$ becomes positive (fault failure) in 2001. For a friction coefficient of 0.75 , the CFS remains negative (the fault remains stable) during the simulation. It increases from the start of the injection operation during the history of injection, and reaches to its maximum in 2001, then decreases till 2005 after which it remains constant. This trend of CFS is mostly affected by
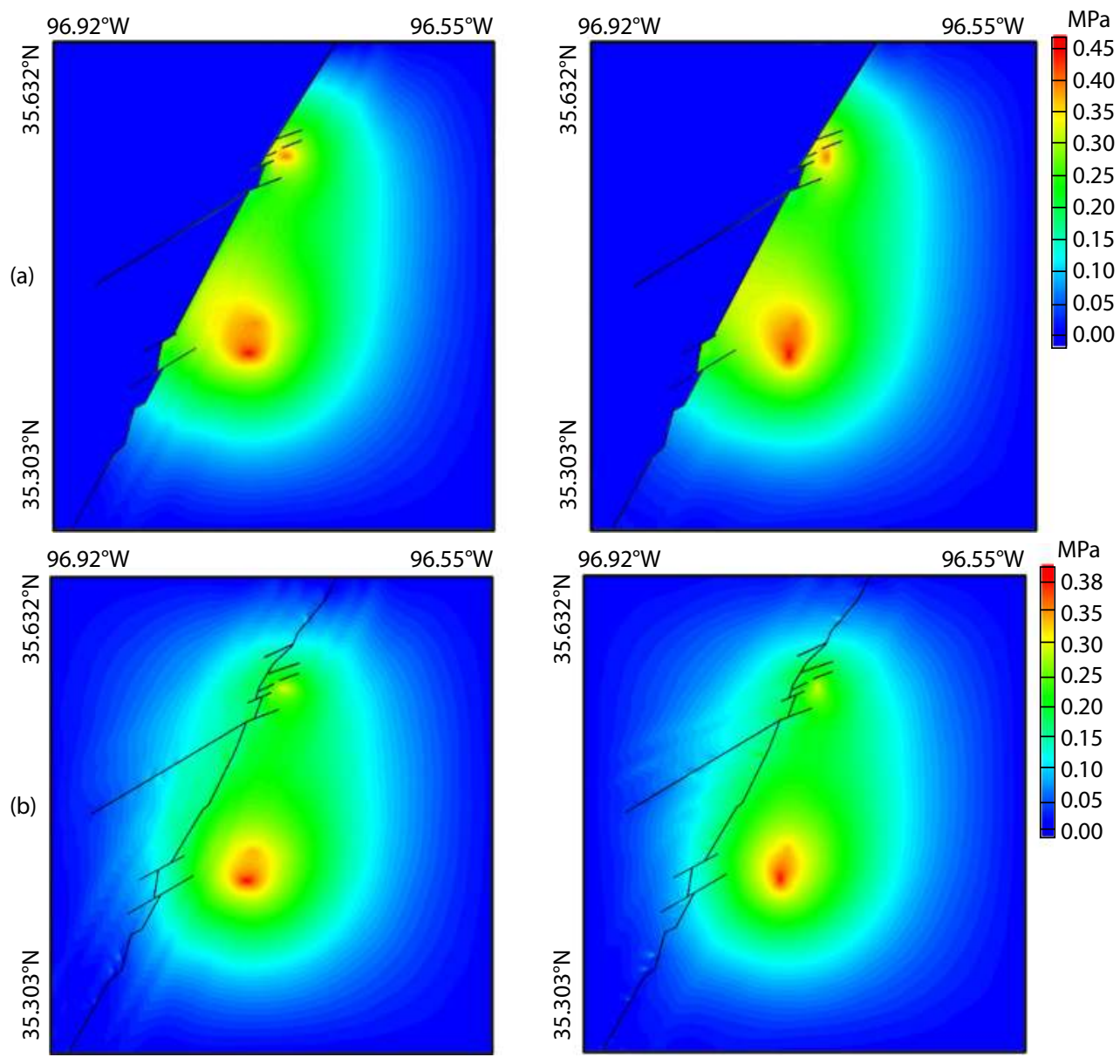

Figure 8. Scenario 1: Change in the horizontal total stresses $\left(\Delta \sigma_{x x}\right.$ and $\left.\Delta \sigma_{y y}\right)$ (MPa) of the Arbuckle group at a depth of $1600 \mathrm{~m}$ in Nov 2011 (after 12 years and 10 months of injection) for (a) case 1 and (b) case 2 induced by injection. $\Delta \sigma_{x x}$ (east-west) and $\Delta \sigma_{y y}$ (north-south) are shown in the left and right figures, respectively. 

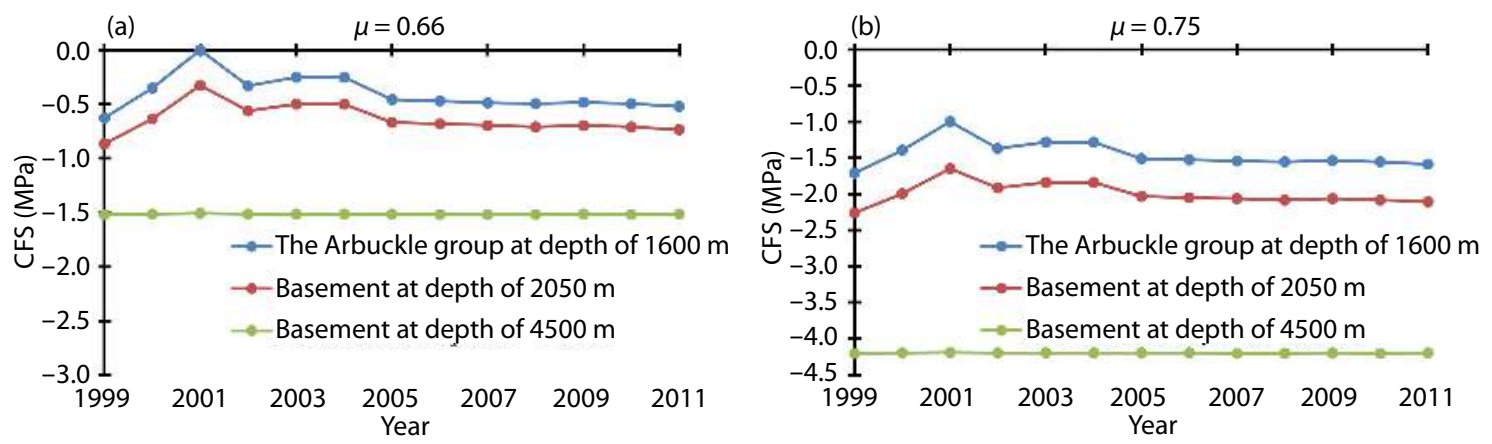

Figure 9. Scenario 1, case 1: Variation of CFS (MPa) at three points located on the fault plane along the dashed line on the splay branch of the Wilzetta fault plane along the cross-section W-W (Figure 7) during simulation for (a) $\mu=0.66$ and (b) $\mu=0.75$. For the value of $\mu=0.66$, CFS becomes positive (fault failure) at depth of $1600 \mathrm{~m}$. The fault remains stable during injection for $\mu=0.75$.
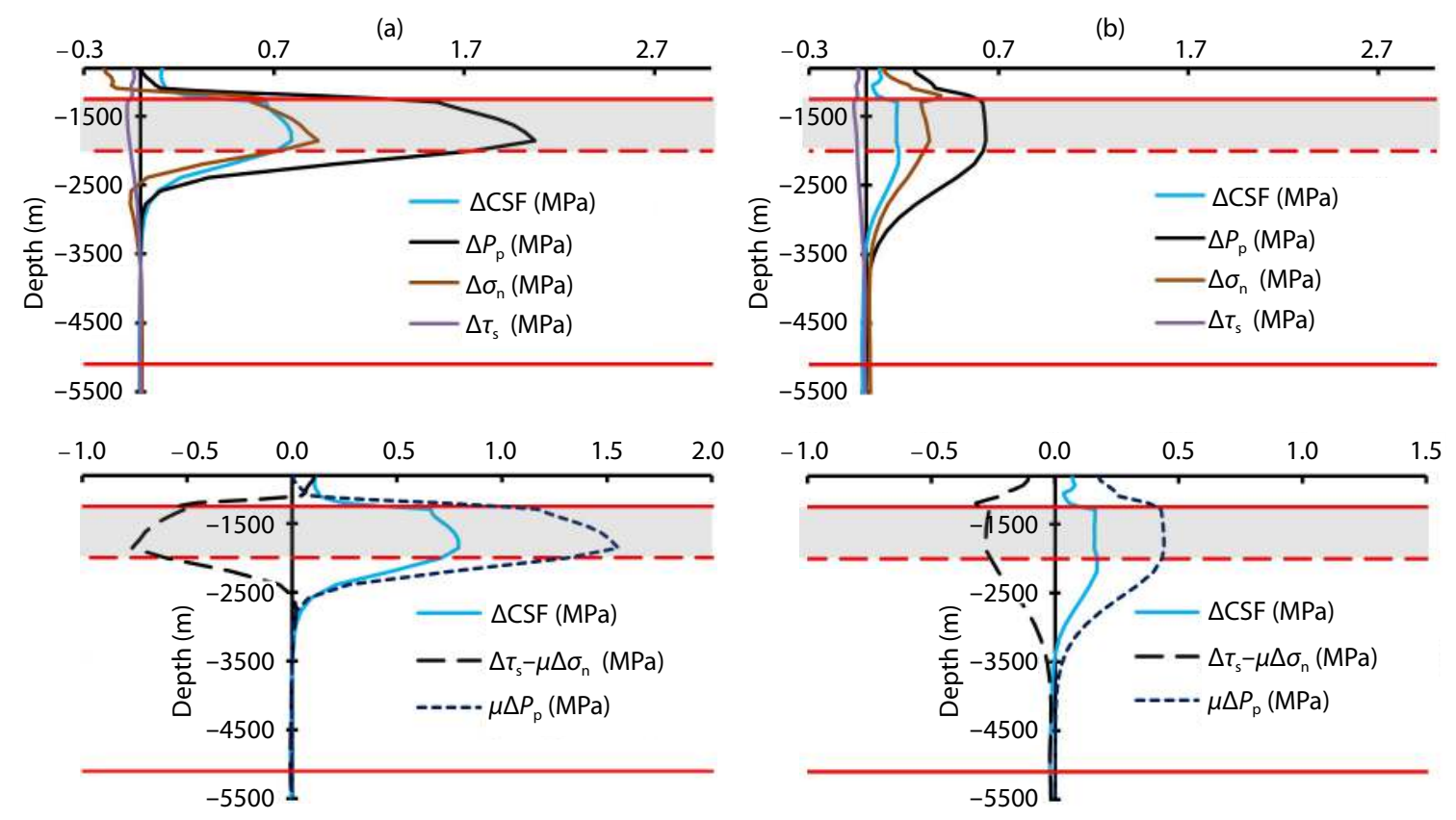

Figure 10. Scenario 1, case 1: Depth profiles of change of CFS (MPa), pore pressure (MPa), total normal stress (MPa), and shear stress (MPa) (upper figure), and profile of change of poroelastic stress (MPa) and pore pressure (MPa) components of $\triangle \mathrm{CFS}$ (lower figure) along the dashed line on the splay branch of the Wilzetta fault plane along the cross-section W-W (Figure 7) in (a) Dec 2001 and (b) Nov 2011. Solid red lines are the fault boundaries. The red dashed line shows the lower boundary of the reservoir $(\mu=0.75)$.

the operation of the Mazkoori well, which has the maximum volume of injection in 2001 and stopped operation at the end of 2004. Since there is no fluid penetration into the deeper depths, CFS remains almost constant at a depth of 4500 m (Figure 9), indicating that no fault reactivation is expected at deeper depth in this case.

Figure 10 depicts the change of components of CFS for both 2001 and $2011(\mu=0.75)$. The total normal stress increases in the reservoir and the part of the basement where fluid diffuses. A reduction in the total normal stress can be observed at the deeper depth in the basement with no fluid diffusion. The shear stress does not change considerably on the fault plane, and remains almost constant. It is evident that the poroelastic stress contribution to the CFS is not enough to cause instability on the fault at deeper locations, and the change in pore pressure $\left(\Delta P_{p}\right)$ is domin- ant at shallower depths. For a value of friction coefficient of $\mu=$ 0.66, CFS becomes positive in 2001 at a depth of $1600 \mathrm{~m}$ (Figure 9), indicating that fault at the shallower depths becomes active before deeper depths. It also shows that due to Mazkoori well operation and its volume of injection, the most critical year is 2001. Figure 11 and Figure 12 present the CFS and change of CFS components for case 2 of scenario 1 , respectively $(\mu=0.75)$. As mentioned before, the excess pore pressure is less than in case 1 because the cross-fault flow is allowed in case 2 . The general trends of the pore pressure, normal stress, and shear stress variations are similar to case 1, but with less tendency for fault reactivation. For example, Figure 11 shows that the fault becomes unstable for a coefficient of friction of 0.63 in 2001 at a depth of 1600 m, while this value is 0.66 for case 1 (Figure 9). Since no events happened in 2001 in reality, we conclude that the assigned properties of the fault and layers need to be modified. Another possible condition 

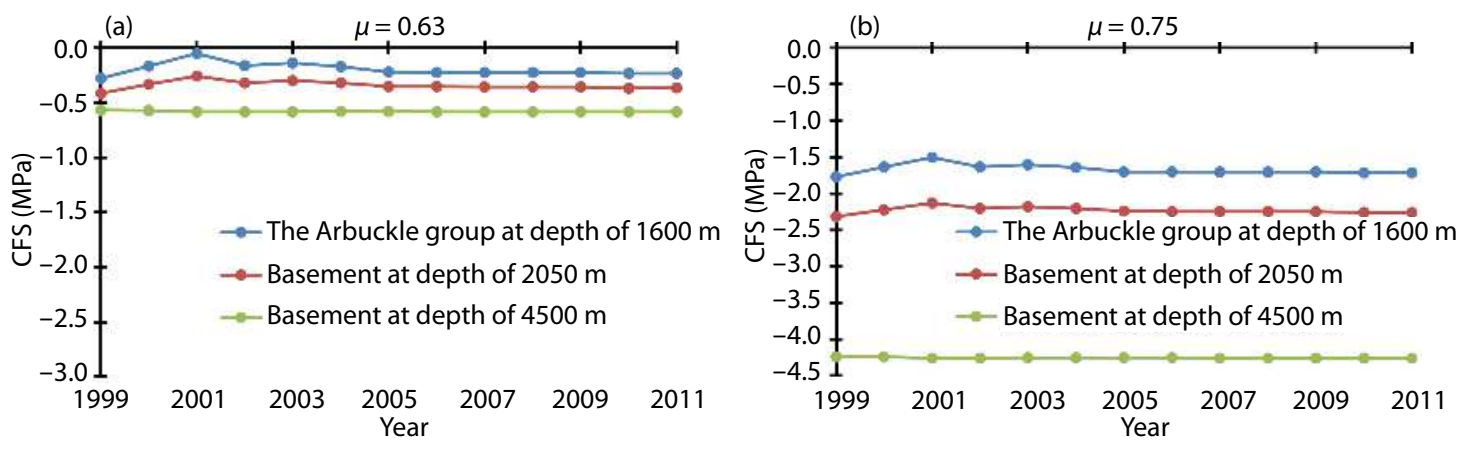

Figure 11. Scenario 1, case 2: Variation of CFS (MPa) at three points located on the fault plane along the dashed line on the splay branch of Wilzetta fault plane along the cross-section W-W (Figure 7) during simulation for (a) $\mu=0.63$ and (b) $\mu=0.75$. For the value of $\mu=0.63$, CFS becomes positive (fault failure) at depth of $1600 \mathrm{~m}$. Due to permeable faults, there is less pressure buildup in this case than in case 1 , and therefore the fault fails at the lower coefficient of friction of 0.63 . The fault remains stable during injection for $\mu=0.75$.

(a)
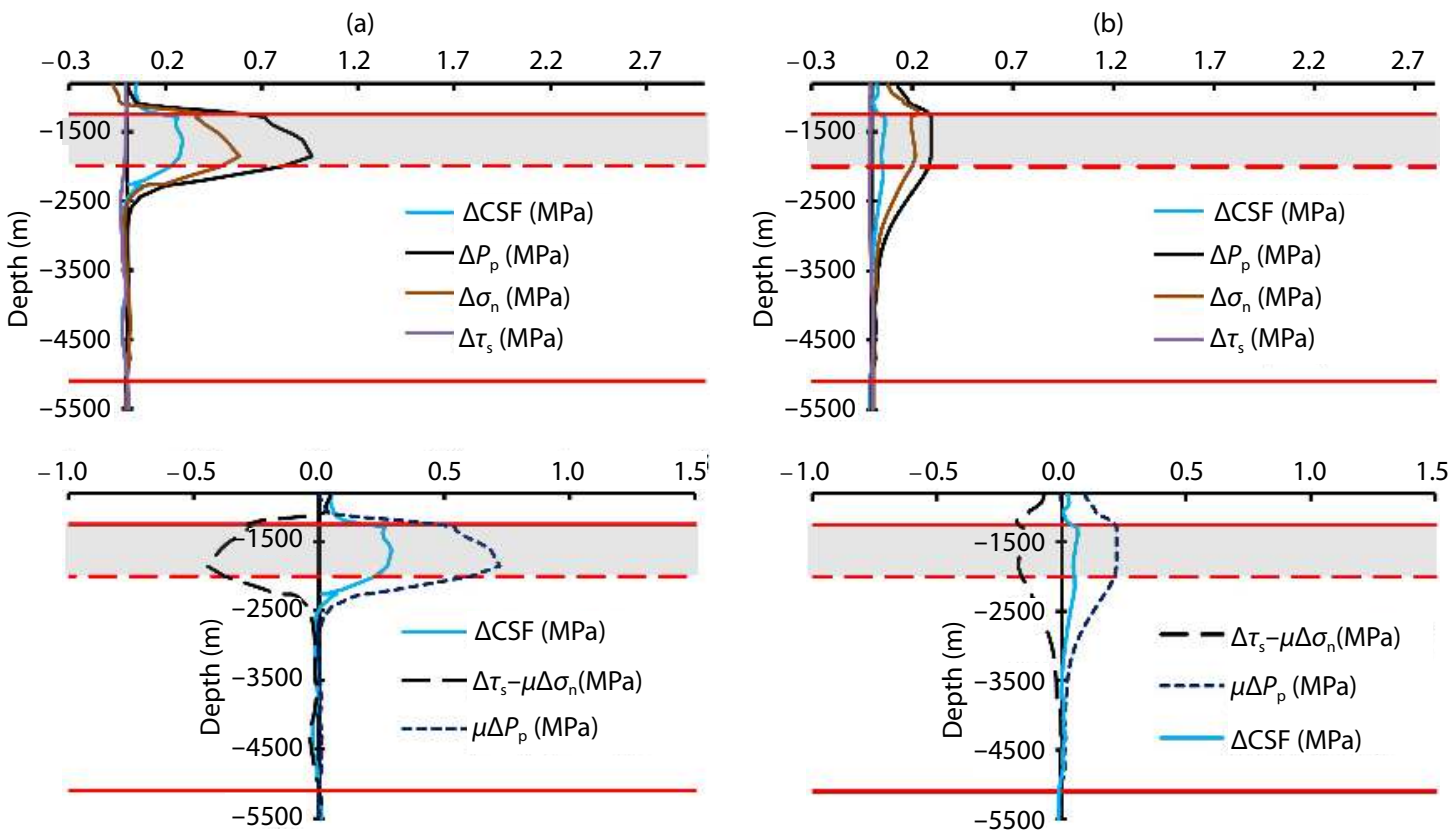

Figure 12. Scenario 1, case 2: Depth profiles of change of CFS (MPa), pore pressure (MPa), total normal stress (MPa), and shear stress (MPa) (upper figure), and profile of change of poroelastic stress (MPa) and pore pressure (MPa) components of $\triangle \mathrm{CFS}$ (lower figure) along the dashed line on the splay branch of Wilzetta fault plane along the cross-section W-w (Figure 7) in (a) Dec 2001 and (b) Nov 2011. Solid red lines are the fault boundaries. The red dashed line shows the lower boundary of the reservoir $(\mu=0.75)$.

is that the mechanical and failure properties of rocks changed during the injection operation which is not captured in the numerical simulations. Note that we assumed a uniform coefficient of friction along the fault.

\subsection{Scenario 1 - Cases 3 and 4: Impermeable and Permeable Faults with High Arbuckle Permeability}

According to Equation (7) and considering the permeability of the Arbuckle group as $100 \mathrm{mD}$, more than $99.9 \%$ of saltwater enters into the Arbuckle group. Our results show that the pressure buildup in both cases 3 and 4 is not high enough to induce instability on the Wilzetta fault. Figure 13 shows the pressure elevation at the end of 2011 at a depth of $1600 \mathrm{~m}$ in the Arbuckle group for cases 3 and 4 . In both cases, the injected water diffuses into the Arbuckle group easily. Therefore, the pressure buildup needed to reactivate the faults is not reached. These cases suggest there is an upper bound for the permeability of the Arbuckle group above which the injected volume (reported by OCC) flows easily in the layer without significant excess pressure build-up, and, in turn, without induced seismicity.

\subsection{Scenario 2: Hydraulic Communication Between Geological Layers via Fault Damage Zones, Low and High Arbuckle Permeability}

In this scenario, it is assumed that there is a damage zone adjacent to the faults through which the injected fluid penetrates the deeper depths where most seismic events were located. We define different cases in the absence of mechanical and hydrological data for the area (Table 3). In cases 1 through 4, both permeable and impermeable faults with different Arbuckle group 

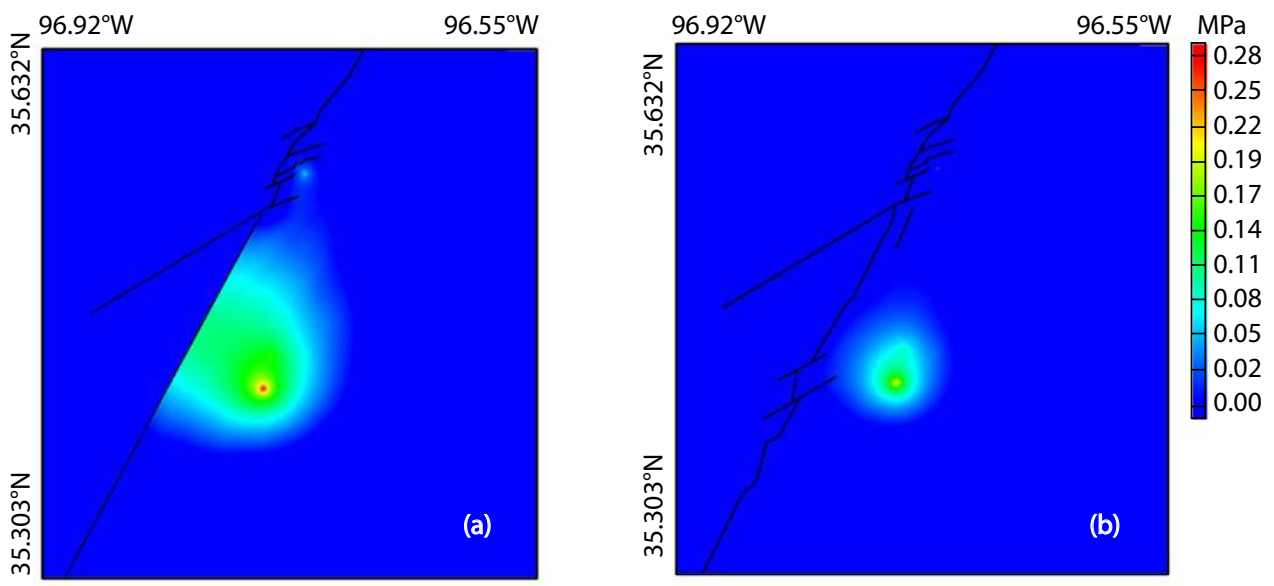

Figure 13. Scenario 1: The change of pore pressure (MPa) in the Arbuckle group at depth of $1600 \mathrm{~m}$ in Nov 2011 (after 12 years and $10 \mathrm{months}$ of injection) for (a) case 3 , and (b) case 4.
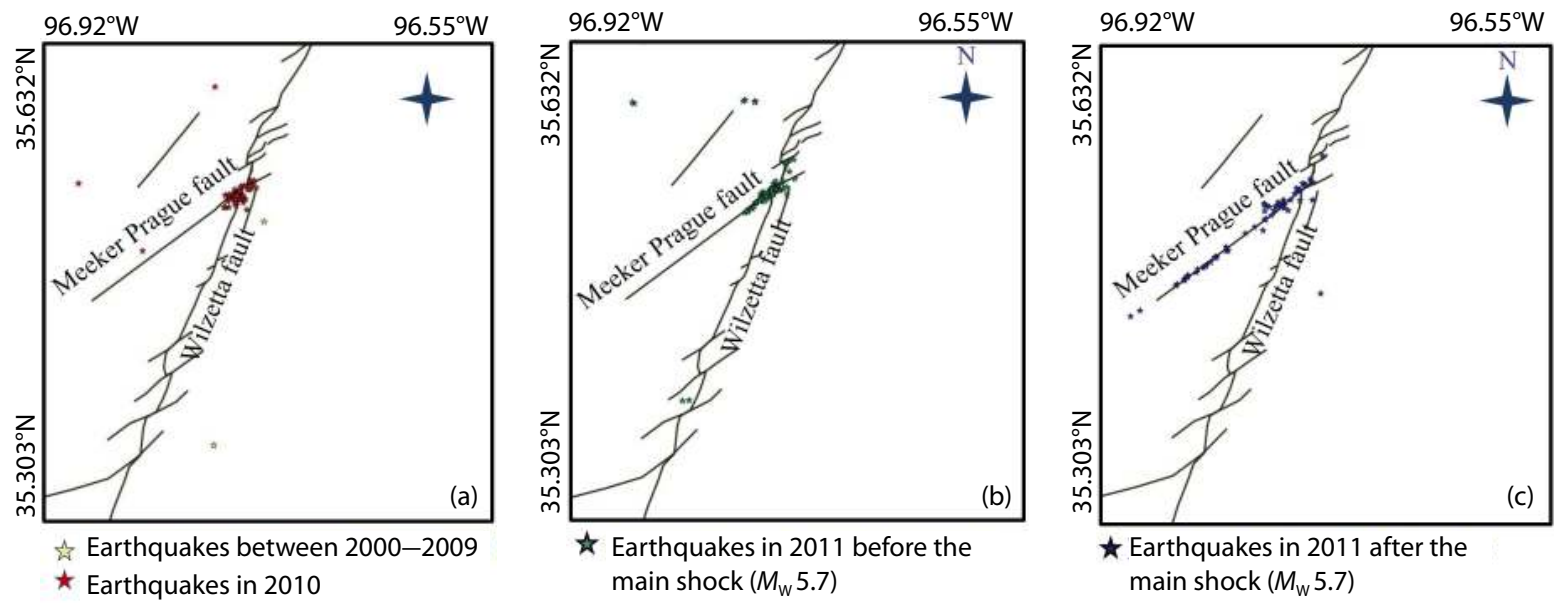

Figure 14. Earthquakes (a) between 2000 and 2010, (b) in 2011 before the mainshock $\left(M_{\mathrm{w}} 5.7\right)$, and (c) in 2011 after the mainshock ( $\left.M_{\mathrm{w}} 5.7\right)(O G S$, http://www.ou.edu/ogs/research/earthquakes/catalogs).

permeabilities of $10 \mathrm{mD}$ and $100 \mathrm{mD}$ are studied. In case 5 , we include the permeability anisotropy of the geological layers and the fault zone. We assume that there is an anisotropy with the ratio of vertical to horizontal permeability of 0.5 , and study the effect of anisotropy on pore pressure distribution. In cases 6 and 7, we evaluate the possibility of the presence of the damage zone in only a portion and some splay branches of the Wilzetta zone (not the whole fault zone in cases 1 to 4 ).

Figure 14 shows the seismic events from 2000 to 2011. It can be seen that between 2000 and 2009, there is no event in the area of interest. In 2010 and 2011, there are many events near the Wilzetta and the Meeker Prague faults intersection. After the main event $\left(M_{\mathrm{w}} 5.7\right.$ on Nov 6, 2011), the events transferred to the south-west direction and occurred mainly on the Meeker Prague fault. This observation suggests a plausible scenario where the damage zone exists only in a portion of the Wilzetta zone and some splay branches. During the years of injection, the induced pore pressure eventually triggers seismic events in both Arbuckle and the basement. Based on this scenario, we define cases 6 and 7 as shown in Figure 5 . In case 6 , the damage zone is assumed only on the portion and some splay branches of the Arbuckle fault as shown by the white dashed line in Figure $5 a$. In case 7, the damage zone is defined only on the splay branch of the Wilzetta fault zone that hosted the foreshocks (Figure 5b). In cases 6 and 7, the effect of the existence of the damage zone only around a portion of Wilzetta fault on the pore pressure elevation and subsequent stress disturbance is studied. Our results indicate that the general responses are similar in different cases of scenario 2, although there are quantitative differences. Therefore, here we only present the results of case 7 in which the highest excess pore pressure is observed.

Figure 15 and Figure 16 show the pore pressure change at the end of 2001, 2005, 2010, and Nov 2011 in the Arbuckle group at depth of $1600 \mathrm{~m}$ and on the splay branch of the Wilzetta fault plane along the cross-section $\mathrm{W}-\mathrm{W}$ for case 7 in scenario 2, respectively. We show that injection induces a pore pressure up to $0.9 \mathrm{MPa}$ in the area between northern and southern wells in both cases in Nov 2011 (Figure 15d). The maximum pore pressure increase of the splay branch of the Wilzetta fault plane along the cross-section W-W is $0.63 \mathrm{MPa}$ after 12 years and 10 months of injection (Figure $16 \mathrm{~d}$ ). In this scenario, in contrast to scenario 1 , the injected fluid diffuses into the deeper depths through the fault 

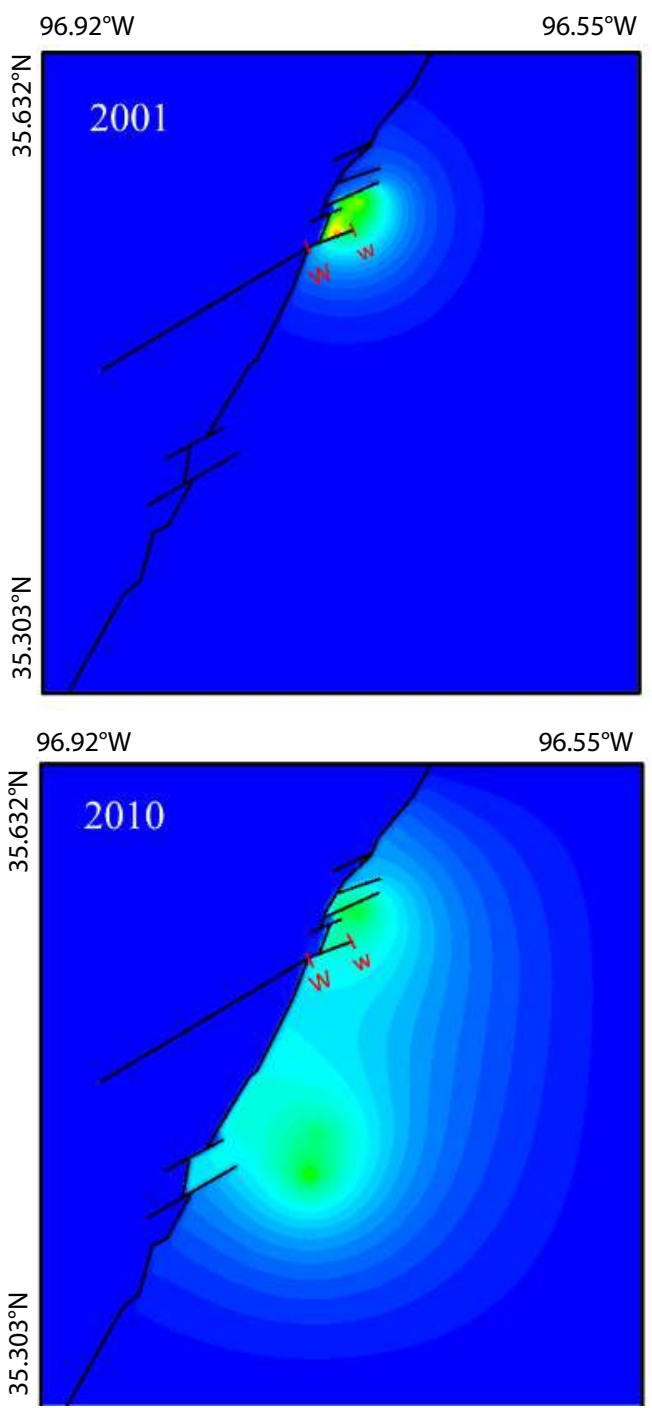

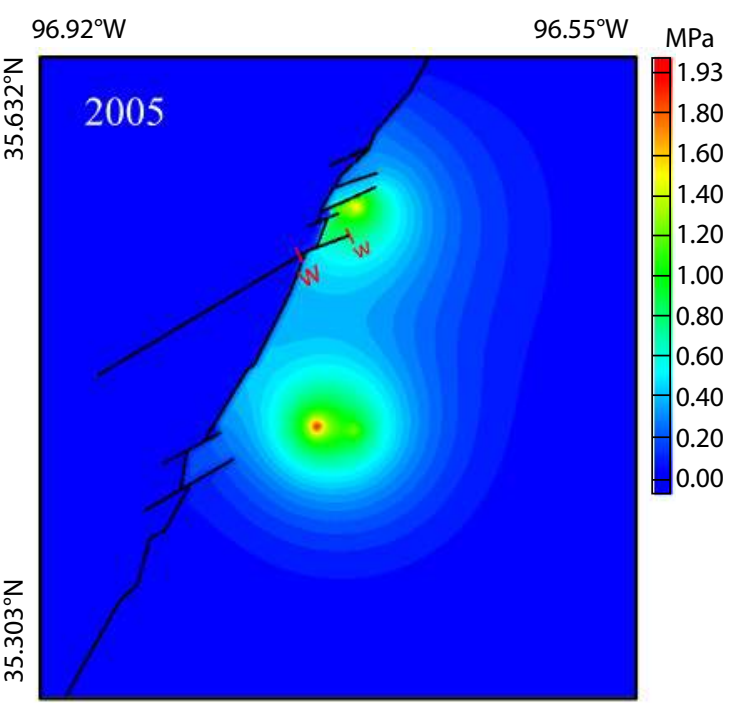

$96.92^{\circ} \mathrm{W} \quad 96.55^{\circ} \mathrm{W}$

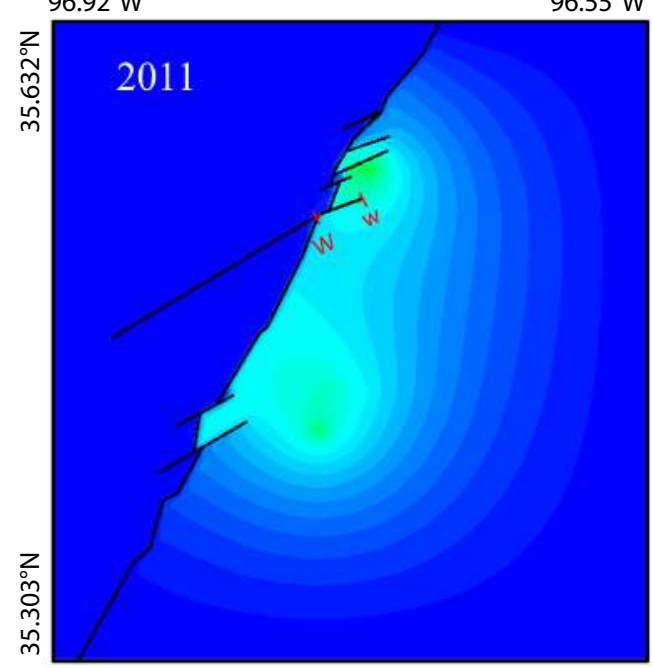

Figure 15. Scenario 2, Case 7: The pore pressure change (MPa) in the Arbuckle group at a depth of $1600 \mathrm{~m}$ at the end of 2001, 2005, 2010, and Nov 2011.

damage zone. This causes more pressure buildup in the fault zone around the basement, and less pressure elevation in the Arbuckle group (Figure 16). The general pattern of pore pressure change of the Arbuckle group is the same as scenario 1, but with lower values. This is because the fluid may flow through the fault damage zone. In 2001, the pore pressure of the Wilzetta fault plane along the cross-section $\mathrm{W}-\mathrm{W}$ has the highest elevation of $1.7 \mathrm{MPa}$ at depth of 1150-1600 m. Similar to scenario 1, the operation of the Mazkoori well during 2000 and 2004 leads to the formation of a high-pressure zone on the splay branch of the Wilzetta fault plane along the cross-section W-W (Figure 16). This high-pressure zone vanishes gradually after Mazkoori well stops operation in 2004, and fluid diffuses into the whole fault damage zone. Eventually, the operation of the other injection wells keeps the pore pressure increase of the Wilzetta fault plane along the cross-section W-W to almost a constant value of $0.6 \mathrm{MPa}$. Note that that in contrast to scenario 1, the injected fluid penetrates deeper where the hypocenters of the main and most foreshock events are located due to the damage zone.

Figure 17 shows the values of the difference between the shear stress and the shear strength (CFS) of the three points at depths of $1600 \mathrm{~m}, 2050 \mathrm{~m}$, and $4500 \mathrm{~m}$ corresponding to the middle of the Arbuckle group, the shallow basement, and the deep basement rocks along the vertical dashed white line (Figure 16, the vertical line on the fault plane that has the shortest distance to the Mazkoori well) on the splay branch of the Wilzetta fault plane along the cross-section $\mathrm{W}-\mathrm{W}$ (Figure 15) during the history of injection (for case 7 of scenario 2). Our results show that the fault reactivation occurred in 2001 for a friction coefficient of 0.65 , and it remains stable for the value of 0.75 . It can be seen that similar to scenario 1, the CFS has the maximum value in 2001 due to the Mazkoori well operation.

Also, the model shows an earthquake would first happen in the Arbuckle group and shallow basement (Figure 17). In contrast to scenario 1, CFS increases at deeper depths and due to the fluid diffusion, but is still not high enough compared to the shallower depths. Note that we estimated these results assuming a uniform frictional property for the fault. Figure 18 shows the depth profile of variation of $\triangle \mathrm{CFS}$ and its components along the white dashed 

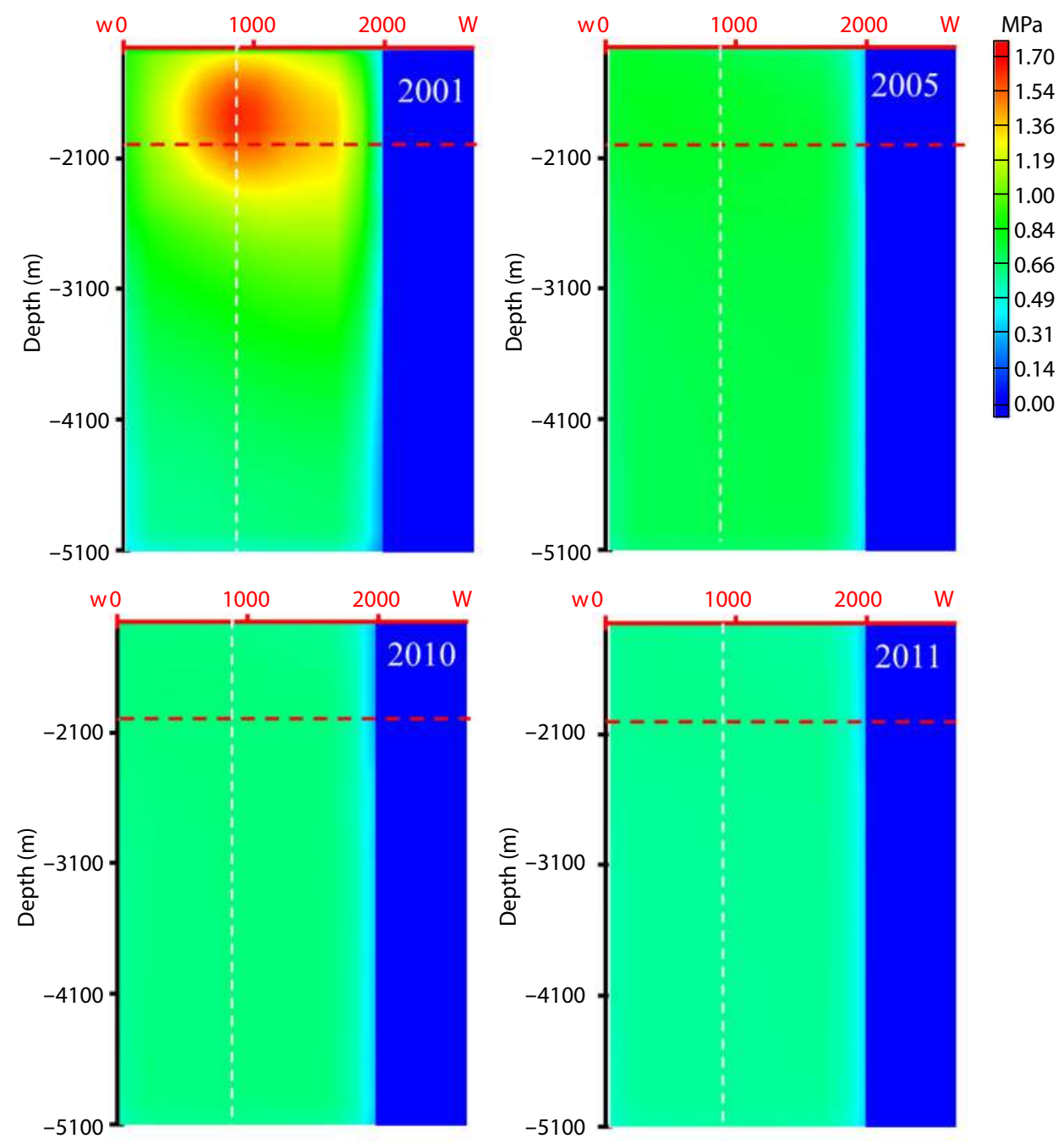

Figure 16. Scenario 2, case 7: The pore pressure change (MPa) on the splay branch of Wilzetta fault plane along the cross-section W-w in Dec 2001, 2005, 2010, and Nov 2011. The top and the lower boundaries of Arbuckle group are shown by the red solid and dashed lines, respectively. The white dashed line is the vertical line on the fault plane that has the shortest distance to the Mazkoori well.
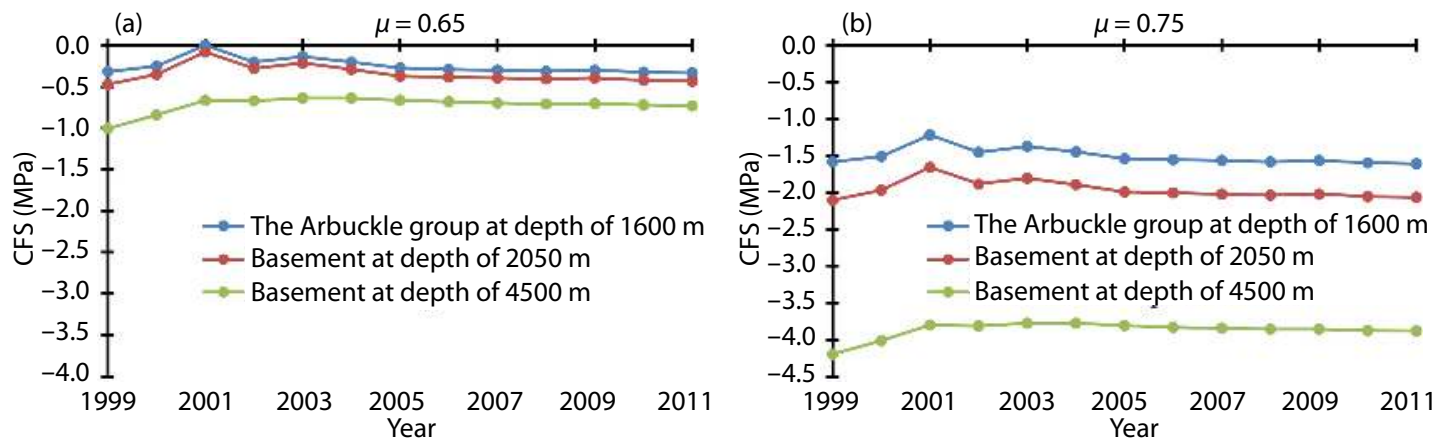

Figure 17. Scenario 2, case 7: Variation of CFS (MPa) at three points located on the fault plane along the white dashed line on the splay branch of Wilzetta fault plane along the cross-section W-W (Figure 16) during simulation for (a) $\mu=0.65$ and (b) $\mu=0.75$. For the value of $\mu=0.65$, CFS becomes positive (fault failure) at depth of $1600 \mathrm{~m}$. The fault remains stable during injection for $\mu=0.75$. At all depths, the CFS has the maximum value due to Mazkoori well operation, and after 2005 remains almost constant.

line (Figure 16). We find that in 2011, when the pore pressure is almost uniform on the fault plane, CFS increase more at deeper zones due to the lower poroelastic process at depth.

\subsection{Scenarios 3: Injection from Mazkoori and Wilzetta Flows into an Isolated Compartment}

We show that in some cases in scenarios 1 and 2, the injection 
(a)

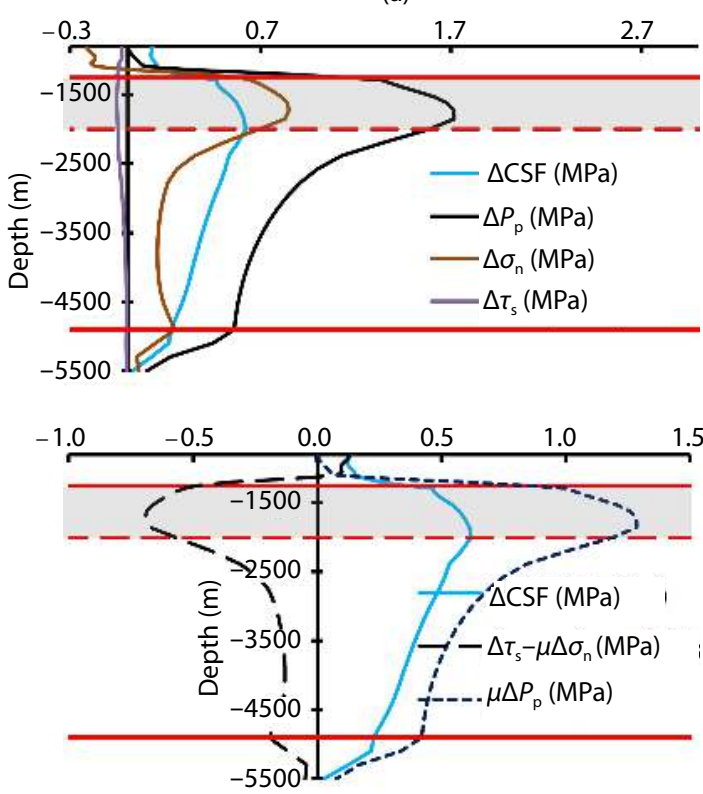

(b)
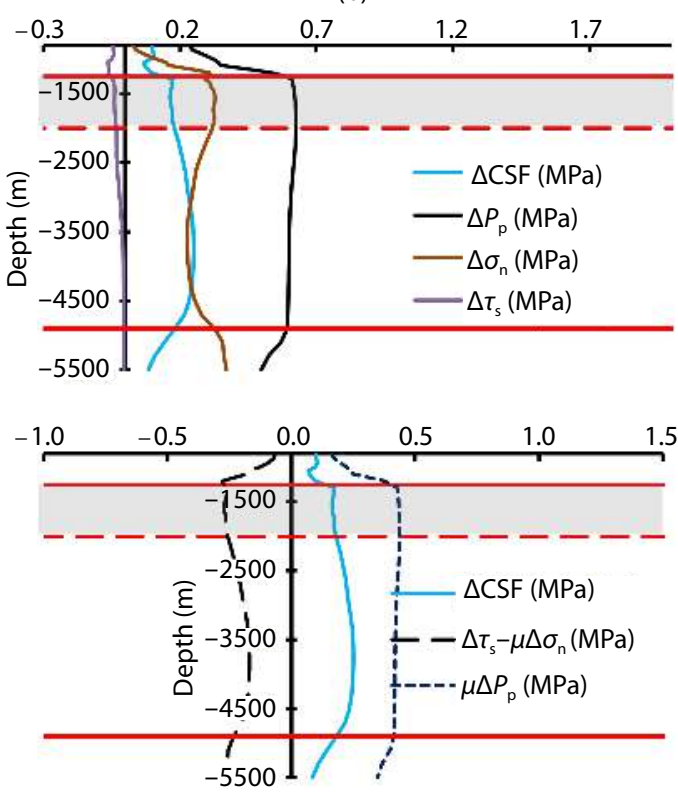

Figure 18. Scenario 2, case 7: Depth profiles of change of CFS (MPa), pore pressure (MPa), total normal stress (MPa), and shear stress (MPa) (Upper figure), and profile of change of poroelastic stress (MPa) and pore pressure (MPa) components of $\Delta$ CFS (Lower figure) along the dashed line on the splay branch of Wilzetta fault plane along the cross-section W-W (Figure 16) in (a) Dec 2001 and (b) Nov 2011. Solid red lines are the fault boundaries. The red dashed line shows the lower boundary of the reservoir $(\mu=0.75)$.

causes elevation of the pore pressure in reservoirs which may remain for many years (even though the eastern side is infinitely open) as observed in the previous studies (Hsieh and Bredehoeft, 1981; Keranen et al., 2013). Both scenarios 1 and 2 show that the injected volume can cause instability on the Wilzetta fault in 2001, i.e., almost 10 years before the 2011 sequence. Therefore, it can be concluded that neither scenarios 1 or 2 can explain the 2011 seismic events.

This strengthens the possibility that in this problem there is an isolated volume where the injected fluid increases the pore pressure which eventually results in the reactivation of the fault. In this scenario, we assume another boundary on the eastern side of the Mazkoori and Wilzetta wells (marked by the white dashed line in Figure 19). We also assume that there is a damage zone as that of case 7 in scenario 2 . Therefore, in contrast to the previous scenarios, the total volume of injected fluid by the Mazkoori and Wilzetta wells diffuses into a bounded volume and causes a continuous increase of the pore pressure. The pore pressure increase at a depth of $1600 \mathrm{~m}$ in the Arbuckle group and on the fault plane along the cross-section W-w are shown in Figure 19 and Figure 20.

The pore pressure increases continuously till it reaches its maximum of 4.25 MPa in 2011. On the fault plane along the cross-section $\mathrm{W}-\mathrm{W}$, this value is $4 \mathrm{MPa}$, and has a pattern different from the previous scenarios. It is evident that even though the Mazkoori well operation finished at the end of 2004, the pore pressure of the fault continues to increase due to the operation of the Wilzetta well.

Figure 21 shows the variation of CFS during the years of simulation at depths of 1600,2050 , and $4500 \mathrm{~m}$ for both $\mu=0.72$ and $\mu=$ 0.75 . Figure 21 a shows that for $\mu=0.72$, the CFS becomes negat- ive (fault failure) at a depth of 1600 in Nov 2011. Figure 21b shows the trend of CFS variation during the simulation for $\mu=0.75$ at which fault remains stable. We find that CFS at depths of 1600 and $2050 \mathrm{~m}$ has some fluctuation due to the activity of Mazkoori well, and increases continuously after 2005. In contrast, CFS increases continuously with a greater slope at a depth of $4500 \mathrm{~m}$. Figure 22 shows the profile of the pore pressure changes and normal stress and shear stress on the fault plane along the cross-section W-W (shown by the white dashed line in Figure 20).

We show that the normal stress increases due to the poroelastic effect when the pore pressure is increased. This increase is more pronounced in the Arbuckle group compared to rocks at deeper depths. Shear stress has a minor change compared to normal stress. In the late years of the history of injection, the pore pressure increase is more uniform on the fault plane than in previous years. However, in contrast, the changes of normal and shear stresses are not uniform. This results in greater increase of the CFS at a deeper depth than the Arbuckle group and shallower depths at the basement. Figure 21 reveals that although CFS increases at a higher rate at deeper depths than shallower ones, still values of CFS in the shallower depths are greater than those at deeper depths. Therefore, the fault reactivation happens at the shallower depths. Note that this conclusion is due to the assumption of a uniform coefficient of friction. Therefore, for example, a greater coefficient of friction for shallower depths, and a lower one at the deeper depths can explain the 2011 sequence spatiotemporally.

\section{Discussion}

There are five high-volume wells (Stasta wells are not highvolume wells compared to other wells, Table 1) in our model among which Mazkoori and Wilzetta have less distance to the 

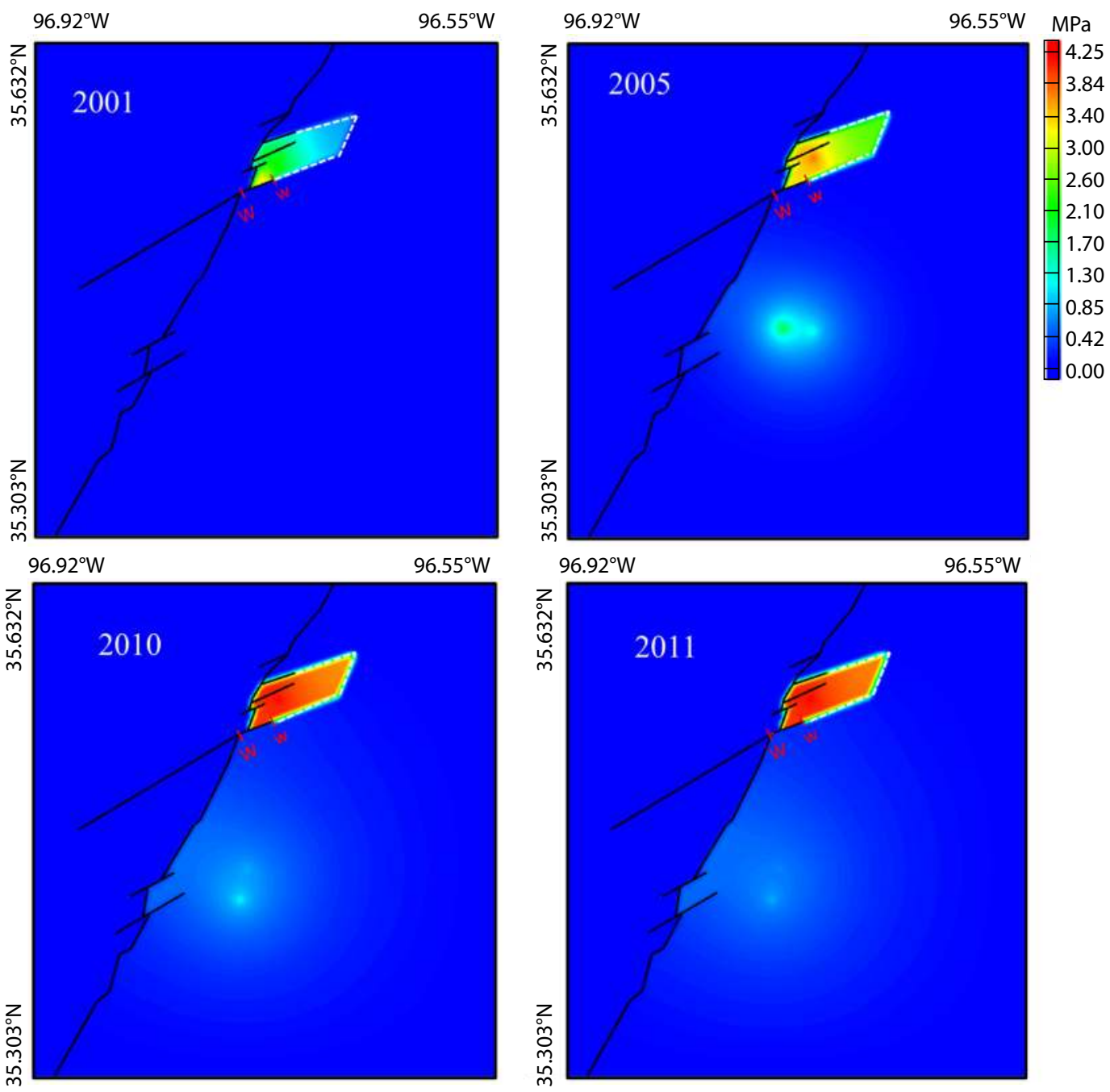

Figure 19. Scenario 3: The pore pressure change (MPa) in the Arbuckle group at a depth of $1600 \mathrm{~m}$ in Dec 2001, 2005, 2010, and Nov 2011. Since the injection is performed in a bounded area, the pore pressure increases continuously compared to scenarios-1 and -2 .

Wilzetta fault. The Mazkoori well is located within less than $200 \mathrm{~m}$ to the portion of the Wilzetta fault on which the 2011 sequence is located, and therefore has the greatest effect. Wilzetta well has a less but still notable effect on the fault, while Hess, Turner, and Howard wells have an insignificant effect on the fault plane pore pressure. Note that the Mazkoori well (the closest well to the fault) operation started in 2000 and finished in 2005 (six years before the 2011 earthquakes). Therefore, there should be a process to explain almost a decade of delay between the start of injection and the 2011 events.

Our model results show that the injected fluid must penetrate the basement via a damage zone to cause fault reactivation at deeper depths. In the absence of such a path, although the poroelastic stress change tends to favor fault reactivation at the deep basement, its magnitude is not enough to induce seismicity. In scenario 1 , we evaluated this condition in which there is no such path and fluid does not penetrate the deep basement, instead, it diffuses only into the target layer. In cases with permeable faults, fluid flows in all directions. In contrast, in cases with impermeable faults, it flows only in the eastern direction. In the deep basement, where there is no fluid diffusion, the poroelastic effect reduces the normal stress effect and tends to reduce the stabilizing normal stress on the fault. This reduction in normal stress (poroelastic effect) is insignificant to cause fault reactivation at deeper depths. Still, the injected fluid by high-volume wells, especially to a greater extent by the Mazkoori well, causes fault reactivation in 2001. However, this does not agree spatiotemporally with what happened in 2011.

There is a damage zone in scenario 2 around the fault through which fluid penetrates to greater depths. To include different plausible situations, we investigated many cases where there is a damage zone around the fault. In the most critical case (case 7), the pore pressure diffuses to the deep basement. It is accompanied by an increase in normal stress (poroelastic effect), which stabilizes the fault. However, still, stability is affected mainly through the direct pore pressure diffusion process and is high enough to induce fault reactivation. The general trend of failure potential variation is however similar to scenario 1 , and fault reactivation happens 10 years before the 2011 sequence in 2001 (due to operation of Mazkoori well) in the Arbuckle group and shallow basement.

In the third scenario, in contrast to other scenarios, we assume an 

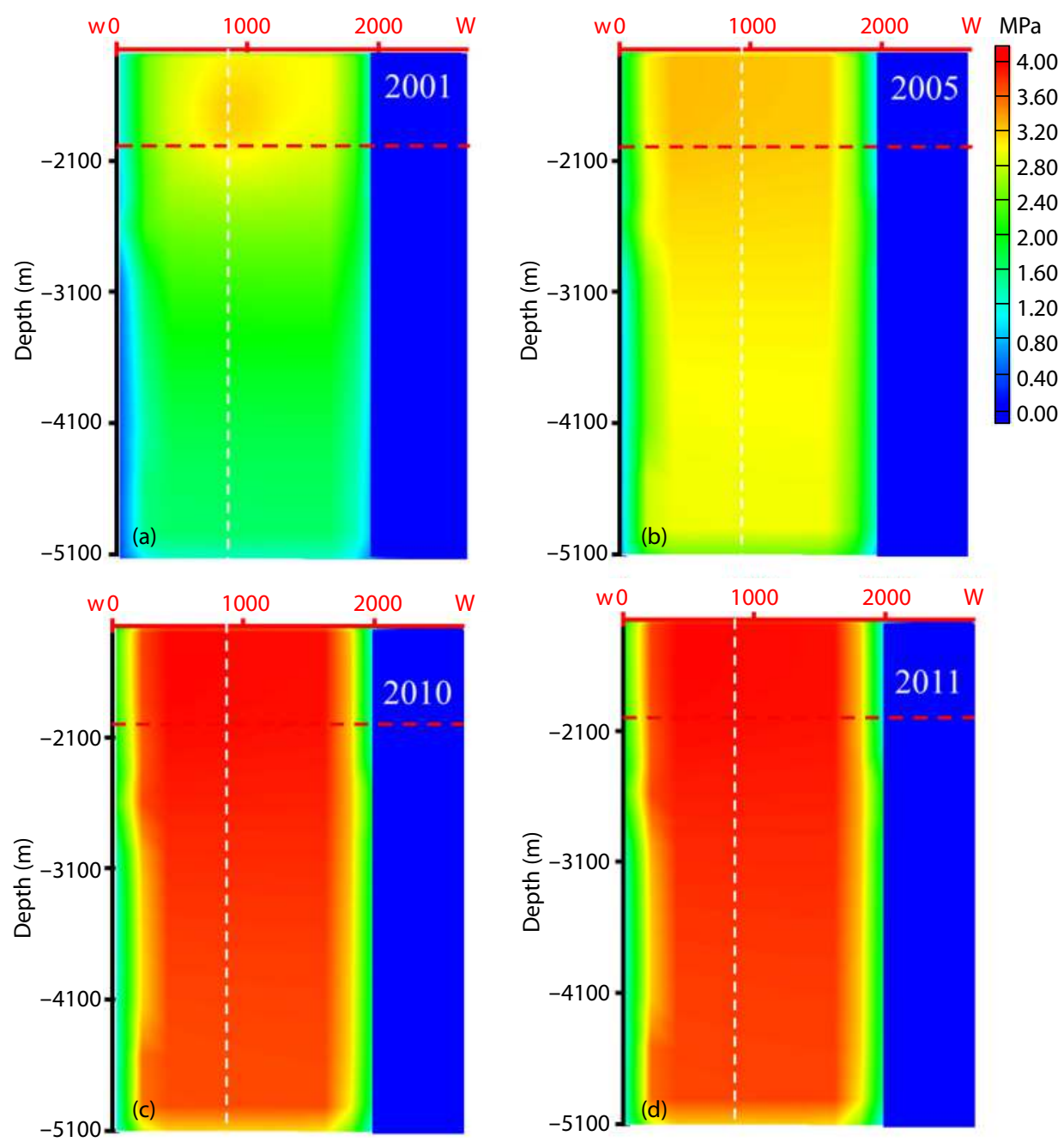

Figure 20. Scenario 3: The pore pressure change (MPa) on the splay branch of the Wilzetta fault plane along the cross-section W-w in Dec 2001, 2005, 2010, and Nov 2011. The Arbuckle group's top and lower boundaries are shown by the red solid and dashed lines, respectively. The white dashed line is a vertical line on the fault plane that has the shortest distance to the Mazkoori well.

effectively sealed compartment into which only Wilzetta and Mazkoori wells inject fluid. We assume the isolated compartment is bounded by the Wilzetta fault (all directions but the eastern side), and define a boundary for the eastern side. Therefore, the reservoir-bounding faults consist of the Wilzetta faults and a fictitious boundary on the eastern side. Our simulations suggest that injection-induced fault instability is plausible in 2011 at the shallow basement and the Arbuckle group. So, in this scenario, in contrast to others, the simulation results have a good temporal agreement with observations. Our simulation suggests that the maximum fault tendency for failure occurs at depths of 3.6 to $3.8 \mathrm{~km}$. Comparing these values with the depth of the main foreshock from OGS $(3.4 \mathrm{~km})$ suggests that the model generally agrees with field data. The difference of 0.2 to $0.4 \mathrm{~km}$ between the real event locations and our model is not highly significant given all of the uncertainties in parameters, and the simplifying assumptions used. For example, assuming a uniform frictional property for the fault can contribute to the discrepancy between the model results and field observations (assuming they are highly accurate). The results show that failure and seismicity potential increase with a higher rate in the deeper basement (compared with the Ar- buckle group and shallow basement) due to a relatively lower increase of the normal stress (poroelastic effect). This scenario reveals that it is unlikely that injection was performed in an infinitely open or semi-restricted reservoir (Wilzetta fault), even with a damage zone. There must be a fault-bounded compartment to create geomechanical conditions conducive to an earthquake in 2011.

\section{Conclusions}

Three earthquakes with $M_{\mathrm{w}}$ of 4.8, 5.7, and 4.8 occurred in November 2011 within the North American midcontinent near Prague, Oklahoma, at a depth of $\sim 5000 \mathrm{~m}$. We carried out a study to simulate the potential contribution of disposal wells to pore pressure and stress perturbations in the fault zone under different permeability structures. In particular, using FLAC3D, we have constructed a coupled fluid-mechanical geomechanical model to study the effect of saltwater injection on the fault reactivation and earthquake sequence in November 2011, based on end-member values for permeability and fault structure. We constructed three main scenarios. In scenario 1 , we assumed that there is no hy- 

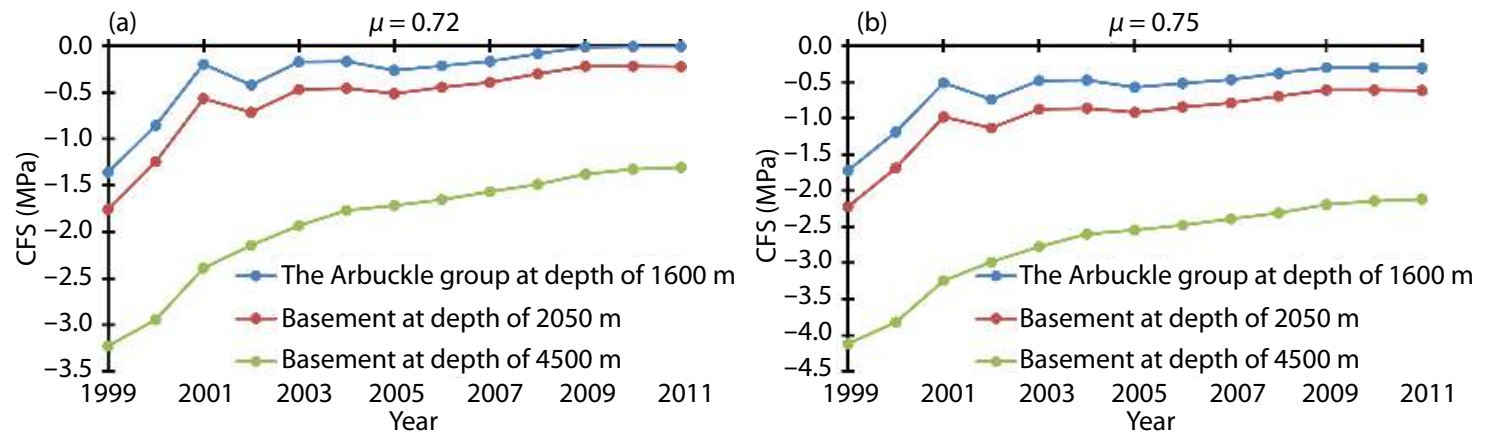

Figure 21. Scenario 3: Variation of CFS (MPa) during simulation for (a) $\mu=0.72$ and (b) $\mu=0.75$. The CFS becomes zero in 2011 at depth of $1600 \mathrm{~m}$ for $\mu=0.72$. In contrast to scenarios 1 and 2, CFS continues to increase at all depths. Due to the poroelastic effect at greater depths, the rate of CFS increase is higher than shallower depths. The fault remains stable during injection for $\mu=0.75$.

(a)
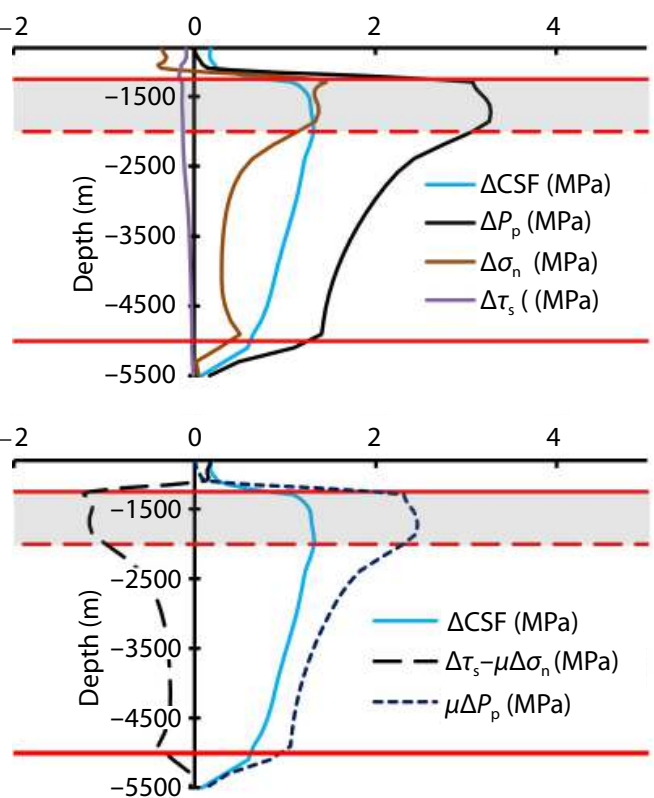

(b)
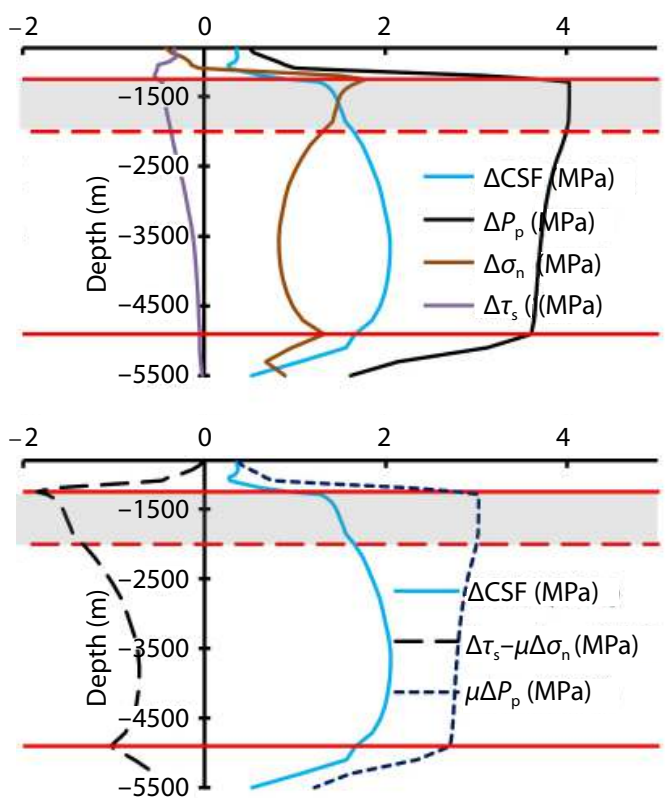

Figure 22. Scenario 3: Depth profiles of change of CFS (MPa), pore pressure (MPa), total normal stress (MPa), and shear stress (MPa) (Upper figure), and profile of change of poroelastic stress (MPa) and pore pressure (MPa) components of $\triangle \mathrm{CFS}$ (Lower Figure) along the dashed line on the splay branch of Wilzetta fault plane along the cross-section W-w (Figure 20) in (a) Dec 2001 and (b) Nov 2011. Solid red lines are the fault boundaries. The red dashed line shows the lower boundary of the reservoir $(\mu=0.75)$.

draulic communication between formation layers subjected to injection. In contrast, a damage zone that acts as a path for fluid to penetrate the deeper depth is considered in scenarios 2 and 3. We especially pay attention to the part of the Wilzetta fault where 2011 foreshocks started, and address whether the pore pressure elevation is capable of causing instability on the fault plane. The following conclusions can be drawn from our simulation: (1) When there is no communication of wastewater between the Arbuckle group and the crystalline basement (e.g., through a damage zone around faults) and the Wilzetta fault is the only barrier to fluid flow (semi-restricted reservoir), the fluid penetrates only to a shallower depth (3.5 km after 11 years of injection). This causes a small destabilizing poroelastic stress in the deeper basement, but this is insufficient to reactivate the fault. The shear stress change is insignificant compared to normal stress change. The model suggests a fault reactivation in 2001 at shallow basement and the reservoir which does not match with reality. (2) When there is a damage zone the fluid penetrates the basement through that, and for either a semi-restricted zone or an infinitely open one, the fluid penetrates deeper into the basement zones, causing a normal stress increase on the fault plane. Yet the simulation shows the pore pressure increase to be enough to reactivate the fault in 2001 at shallow basement and in the Arbuckle group; this does not agree with what happened in the 2011 sequence. (3) In scenario 3 , in contrast to other scenarios, we assume that the injection zone is not semi-restricted, and the fluid is pumped into a fully bounded volume. The simulation for this scenario shows a continuous increase of pore pressure which eventually leads to fault reactivation in 2011 which is in good agreement with reality. Based on our model, the poroelastic stress increases the tendency of fault reactivation at a relatively deeper zone of 3.6 to $3.8 \mathrm{~km}$, whereas the actual main foreshock occurred at a depth of $3.4 \mathrm{~km}$. 
These findings suggest that our model reflects the general response of the Wilzetta fault zone to the injection well. However, the model simplification, data idealization, and assumptions may be responsible for this apparent difference.

Overall, the numerical results show that the volume of injection is sufficient to yield the fault instability based on the reported in-situ stress magnitudes, fault geometry (Wizletta and Meeker-Prague faults), and hydromechanical properties of different rock layers. However, modeling idealization of the subsurface conditions causes a discrepancy between the time of occurrence of instability and potential seismicity in numerical simulations. Oklahoma basement rocks can become seismically unstable under in-situ depth conditions of temperature, pressure, and water saturation of 3-6 km at depth, and tend to slip unstably instead of creep (Kolawole et al., 2019). More data regarding the fault systems and the geological units and their hydrological properties are needed to enable a more accurate analysis to help improve and manage the injection operations to minimize risks.

\section{References}

Alt II, R. C. , and Zoback, M. D. (2014). Development of a detailed stress map of Oklahoma for avoidance of potentially active faults when siting wastewater injection wells. In Proceedings of Fall Meeting 2014. San Francisco: AGU.

Alt II, R. C., and Zoback, M. D. (2017). In situ stress and active faulting in Oklahoma. Bull. Seismol. Soc. Am., 107(1), 216-228.

https://doi.org/10.1785/0120160156

Antonellini, M., and Aydin, A. (1994). Effect of faulting on fluid flow in porous sandstones: petrophysical properties. AAPG Bulletin, 78(3), 355-377.

Bear, J. (2013). Dynamics of Fluids in Porous Media. Courier Corporation.

Biot, M. A. (1941). General theory of three-dimensional consolidation. J. Appl. Phys., 12(2), 155-164. https://doi.org/10.1063/1.1712886

Byerlee, J. (1978). Friction of rocks. In J. D. Byerlee, et al. (Eds. ), Rock Friction and Earthquake Prediction (pp. 615-626). Birkhäuser, Basel: Springer. https://doi.org/10.1007/978-3-0348-7182-2_4

Caine, J. S., Evans, J. P., and Forster, C. B. (1996). Fault zone architecture and permeability structure. Geology, 24(11), 1025-1028. https://doi.org/10.1130/0091-7613(1996)024<1025:FZAAPS >2.3.CO;2

Cappa, F. (2009). Modeling fluid transfer and slip in a fault zone when integrating heterogeneous hydromechanical characteristics in its internal structure. Geophys. J. Int., 178(3), 1357-1362. https://doi.org/10.1111/j.1365246X.2009.04291.X

Carrell, J. R. (2014). Field-scale hydrogeologic modeling of water injection into the Arbuckle zone of the midcontinent [Doctoral dissertation]. Oklahoma: University of Oklahoma.

Cheng, A. H. D. (2016). Poroelasticity (pp. 1-877). Cham, Switzerland: Springer.

Chester, F. M., and Logan, J. M. (1986). Implications for mechanical properties of brittle faults from observations of the Punchbowl fault zone, California. Pure Appl. Geophys., 124(1-2), 79-106. https://doi.org/10.1007/BF00875720

Chester, F. M., Evans, J. P., and Biegel, R. L. (1993). Internal structure and weakening mechanisms of the San Andreas fault. J. Geophys. Res. :Solid Earth, 98(B1), 771-786. https://doi.org/10.1029/92JB01866

Dart, R. L. (1990). In Situ Stress Analysis of Wellbore Breakouts from Oklahoma and the Texas Panhandle (pp. 1-36). Washington: USGS.

Deng, K., Liu, Y. J., and Chen, X. W. (2020). Correlation between poroelastic stress perturbation and multidisposal wells induced earthquake sequence in Cushing, Oklahoma. Geophys. Res. Lett., 47(20), e2020GL089366. https://doi.org/10.1029/2020GL089366

Dycus, M. N. (2013). Structural characterization of the wilzetta fault zone: lincoln, Pottawatomie, and Creek Counties, Oklahoma [Doctoral dissertation]. Tulsa: University of Tulsa.

Frohlich, C., Hayward, C., Stump, B., and Potter, E. (2011). The dallas-fort worth earthquake sequence: October 2008 through May 2009. Bull. Seismol. Soc.
Am., 101(1), 327-340. https://doi.org/10.1785/0120100131

Frohlich, C., Ellsworth, W., Brown, W. A., Brunt, M., Luetgert, J., MacDonald, T., and Walter, S. (2014). The 17 May 2012 M4.8 earthquake near Timpson, East Texas: an event possibly triggered by fluid injection. J. Geophys. Res.: Solid Earth, 119(1), 581-593. https://doi.org/10.1002/2013JB010755

Gan, Q., and Elsworth, D. (2014). Analysis of fluid injection-induced fault reactivation and seismic slip in geothermal reservoirs. J. Geophys. Res. :Solid Earth, 119(4), 3340-3353. https://doi.org/10.1002/2013JB010679

Gao, Q., and Ghassemi, A. (2020). Finite element simulations of 3D planar hydraulic fracture propagation using a coupled hydro-mechanical interface element. Int. J. Numer. Anal. Meth. Geomech., 44(15), 1999-2024. https://doi.org/10.1002/nag.3116

Ghassemi, A., and Tao, Q. F. (2016). Thermo-poroelastic effects on reservoir seismicity and permeability change. Geothermics, 63, 210-224. https://doi.org/10.1016/j.geothermics.2016.02.006

Hair, T. J. (2012). Constructing a geomechanical model of the Woodford Shale, Cherokee Platform, Oklahoma, USA effects of confining stress and rock strength on fluid flow [Doctoral dissertation]. Texas: Texas Christian University.

Healy, J. H., Rubey, W. W., Griggs, D. T., and Raleigh, C. B. (1968). The Denver earthquakes. Science, 161(3848), 1301-1310. https://doi.org/10.1126/science.161.3848.1301

Holland, A. A. , Keller Jr, G. R. , Darold, A. P. , Murray, K. E. , and Holloway, S. D. (2014). Multidisciplinary approach to identify and mitigate the hazard from induced seismicity in Oklahoma. In Proceedings of Fall Meeting 2014 (pp. U34A-04). Washington: American Geophysical Union.

Hooker, V. E. , and Johnson, C. F. (1969). Near-surface Horizontal Stresses Including the Effects of Rock Anisotropy (Vol. 7224). Pittsburgh: US Bureau of Mines.

Horton, S. (2012). Disposal of hydrofracking waste fluid by injection into subsurface aquifers triggers earthquake swarm in central Arkansas with potential for damaging earthquake. Seismol. Res. Lett., 83(2), 250-260. https://doi.org/10.1785/gssrl.83.2.250

Hough, S. E. (2014). Shaking from injection-induced earthquakes in the central and eastern United States. Bull. Seismol. Soc. Am., 104(5), 2619-2626. https://doi.org/10.1785/0120140099

Hsieh, P. A., and Bredehoeft, J. D. (1981). A reservoir analysis of the Denver earthquakes: a case of induced seismicity. J. Geophys. Res. :Solid Earth, 86(B2), 903-920. https://doi.org/10.1029/JB086iB02p00903

Itasca Consulting Group Inc. (2012). Fast Lagrangian Analysis of Continua in 3 Dimensions User's MANUAL. Minneapolis, MN, USA: Itasca Consulting Group Inc.

Keller, G. R. , and Holland, A. (2013). Oklahoma Geological Survey evaluation of the Prague earthquake sequence of 2011. Norman, OK: Oklahoma Geological Survey.

Keranen, K. M., Savage, H. M., Abers, G. A., and Cochran, E. S. (2013). Potentially induced earthquakes in Oklahoma, USA: links between wastewater injection and the $2011 \mathrm{M}_{\mathrm{w}} 5.7$ earthquake sequence. Geology, 41(6), 699-702. https://doi.org/10.1130/G34045.1

Keranen, K. M., Weingarten, M., Abers, G. A., Bekins, B. A., and Ge, S. (2014). Sharp increase in central Oklahoma seismicity since 2008 induced by massive wastewater injection. Science, 345(6195), 448-451. https://doi.org/10.1126/science. 1255802

Kim, W. Y. (2013). Induced seismicity associated with fluid injection into a deep well in Youngstown, Ohio. J. Geophys. Res. :Solid Earth, 118(7), 3506-3518. https://doi.org/10.1002/jgrb.50247

Kolawole, F., Johnston, C. S., Morgan, C. B., Chang, J. C., Marfurt, K. J., Lockner, D. A., Reches, Z., and Carpenter, B. M. (2019). The susceptibility of Oklahoma's basement to seismic reactivation. Nat. Geosci., 12(10), 839-844. https://doi.org/10.1038/s41561-019-0440-5

Kolawole, F., Turko, M. S., and Carpenter, B. M. (2020). Basement-controlled deformation of sedimentary sequences, Anadarko Shelf, Oklahoma. Basin Res., 32(6), 1365-1387. https://doi.org/10.1111/bre.12433

Lorenz, J. C., Teufel, L. W., and Warpinski, N. R. (1991). Regional fractures I: A mechanism for the formation of regional fractures at depth in flat-lying reservoirs. AAPG Bull., 75(11), 1714-1737. 
McGarr, A., Simpson, D., and Seeber, L. (2002). Case histories of induced and triggered seismicity. Int. Geophys., 81, 647-661. https://doi.org/10.1016/S0074-6142(02)80243-1

Murray, K. E., and Holland, A. A. (2014). Inventory of class II underground injection control volumes in the midcontinent. Shale Shaker, 65(2), 98-106.

National Research Council. (2013). Induced Seismicity Potential in Energy Technologies. Washington: National Academies Press.

Nelson, P. H., Gianoutsos, N. J., and Drake, R. M. (2015). Underpressure in Mesozoic and Paleozoic rock units in the Midcontinent of the United States. AAPG Bulletin, 99(10), 1861-1892. https://doi.org/10.1306/04171514169

Oklahoma Geological Survey (OGS). http://www.ou.edu/ogs/data/ fault

Oklahoma Corporation Commission (OCC). http://www.occeweb.com/og/ogdatafiles2.htm

OGS. http://www.ou.edu/ogs/research/earthquakes/catalogs

Pearson, C. (1981). The relationship between microseismicity and high pore pressures during hydraulic stimulation experiments in low permeability granitic rocks. J. Geophys. Res. :Solid Earth, 86(B9), 7855-7864. https://doi.org/10.1029/JB086iB09p07855

Petersen, M. D., Mueller, C. S., Moschetti, M. P., Hoover, S. M., Shumway, A. M., McNamara, D. E., Williams, R. A., Llenos A. L., Ellsworth, W. L., ... Rukstales, K. S. (2017). One-year seismic-hazard forecast for the central and eastern united states from induced and natural earthquakes. Seismological Research Letters, 88(3), 772-783. https://doi.org/10.1785/0220170005

Phillips, W. S., House, L. S., and Fehler, M. C. (1997). Detailed joint structure in a geothermal reservoir from studies of induced microearthquake clusters. J. Geophys. Res. :Solid Earth, 102(B6), 11745-11763. https://doi.org/10.1029/97JB00762

Raleigh, C. B., Healy, J. H., and Bredehoeft, J. D. (1976). An experiment in earthquake control at Rangely, Colorado. Science, 191(4233), 1230-1237. https://doi.org/10.1126/science.191.4233.1230

Rice, J. R., and Cleary, M. P. (1976). Some basic stress diffusion solutions for fluid-saturated elastic porous media with compressible constituents. Rev. Geophys., 14(2), 227-241. https://doi.org/10.1029/RG014i002p00227

Rinaldi, A. P., Jeanne, P., Rutqvist, J., Cappa, F., and Guglielmi, Y. (2014). Effects of fault-zone architecture on earthquake magnitude and gas leakage related to $\mathrm{CO}_{2}$ injection in a multi-layered sedimentary system. Green.
Gases:Sci. Technol., 4(1), 99-120. https://doi.org/10.1002/ghg.1403

Rutqvist, J., Wu, Y. S., Tsang, C. F., and Bodvarsson, G. (2002). A modeling approach for analysis of coupled multiphase fluid flow, heat transfer, and deformation in fractured porous rock. International Journal of Rock Mechanics and Mining Sciences, 39(4), 429-442. https://doi.org/10.1016/S1365-1609(02)00022-9

Segall, P. (1989). Earthquakes triggered by fluid extraction. Geology, 17(10), 942-946. https://doi.org/10.1130/00917613(1989)017<0942:ETBFE>2.3.CO;2

Statler, A. T. (1965). Stratigraphy of the Simpson group in Oklahoma. Tulsa Geol. Soc. Dig., 33, 162-209.

Suckale, J. (2009). Induced seismicity in hydrocarbon fields. Adv. Geophys., 51 55-106. https://doi.org/10.1016/S0065-2687(09)05107-3

Sumy, D. F., Cochran, E. S., Keranen, K. M., Wei, M. Y., and Abers, G. A. (2014). Observations of static Coulomb stress triggering of the November 2011 M5.7 Oklahoma earthquake sequence. J. Geophys. Res. :Solid Earth, 119(3), 1904-1923. https://doi.org/10.1002/2013JB010612

Sun, X. D., and Hartzell, S. (2014). Finite-fault slip model of the $2011 \mathrm{M}_{\mathrm{w}} 5.6$ Prague, Oklahoma earthquake from regional waveforms. Geophys. Res. Lett., 41(12), 4207-4213. https://doi.org/10.1002/2014GL060410

von Schonfeldt, H. A., Kehle, R. O., and Gray. K. E. (1973). Mapping of stress field in the upper Earth's crust of the US. Final technical report. grant 14-08-00011222, US Geological Survey, Reston, Va.

Walters, R. F. (1958). Differential entrapment of oil and gas in Arbuckle dolomite of central Kansas. AAPG Bull., 42(9), 2133-2173.

Way, H. S. K. (1983). Structural Study of the Hunton Lime of the Wilzetta Field T12-13N, R5E, Lincoln County, Oklahoma, Pertaining to the Exploration for Hydrocarbons [Doctoral dissertation]. Oklahoma State University.

Yu, W. Q. (2017). Laboratory geomechanical characterization of the Arbuckle group and crystalline basement rocks in Oklahoma [Doctoral dissertation]. Oklahoma: University of Oklahoma.

Yu, W. Q. , and Ghassemi, A. (2017). Laboratory geomechanical characterization of the Arbuckle Group in Oklahoma. In Proceedings of the 51st U. S. Rock Mechanics/Geomechanics Symposium. San Francisco: American Rock Mechanics Association. 